\title{
Los valores de la Economía Social como impulsores del cambio en clústeres con fuerte fragmentación del conocimiento: el caso de la caña de azúcar de Veracruz (México)
}

\author{
Juan R. Gallego-Bono \\ María R. Tapia-Baranda
}

RESUMEN: La literatura evolucionista sobre innovación tecnológica se ha desarrollado bastante independientemente de la investigación sobre innovación social. El presente artículo intentará evidenciar que en los clústeres de América Latina la innovación social constituye una precondición para poner en valor los conocimientos locales. Este reconocimiento permite enfrentar la tensión dialéctica fragmentación/integración del conocimiento existente en estos clústeres. Se esboza un marco teórico evolucionista en el que la innovación social, y en especial los nuevos valores, constituyen el vehículo de la entrada en escena de los motores de la transformación sectorial y territorial en los clústeres agroindustriales: nuevos actores, nuevas competencias y nuevas relaciones. Con este marco conceptual, se analiza la dinámica del clúster de la caña de azúcar sobre la base de una metodología cualitativa basada esencialmente en la realización de entrevistas en profundidad.

La producción de caña de azúcar es el motor económico de la región del centro de Veracruz (México). Pero la fuerte integración vertical del sector y la fragmentación del conocimiento en el clúster azucarero han contribuido a la rápida descomposición social de la región y a la acentuación de la violencia y la exclusión social. En este contexto, se mostrará el papel de los valores de la economía social en la renovación de las actividades y en la reorganización local de la cadena de valor con una orientación hacia un desarrollo más sostenible. Todo ello, de la mano de la irrupción de nuevas empresas (PYMES) portadoras de nuevas visiones, planteamientos y competencias que desafían las posiciones establecidas.

PALABRAS CLAVE: Fragmentación del conocimiento, Discriminación, Valores de la economía social, Innovación social, Caña de azúcar, México.

CLAVES ECONLIT: D83, 013, 035, Q13, Q18, R11.

Cómo citar este artículo / How to cite this article: GALLEGO-BONO, J.R. \& TAPIA-BARANDA, M.R. (2019):

"Los valores de la economía social como impulsores del cambio en clústeres con fuerte fragmentación del conocimiento: el caso de la caña de azúcar de Veracruz (México)", CIRIEC-España, Revista de Economía Pública, Social y Cooperativa, 97, 75-109. DOI: 10.7203/CIRIEC-E.97.14108.

Correspondencia: Juan Ramón Gallego-Bono, Departament d'Economia Aplicada, Universitat de València, Juan.R.Gallego@uv.es, y María Rosario Tapia-Baranda, doctoranda en Economía Social, Universitat de València, tapiacharis@gmail.com. 


\section{EXPANDED ABSTRACT}

\section{The values of the social economy as drivers of change in clusters with a strong fragmentation of knowledge: the case of sugar cane in Veracruz (Mexico)}

Frequently, clusters in developing countries are characterized by a strong fragmentation of knowledge rooted in an intense concentration of economic and political power. This concentration of power forms the basis for the generation of innovation networks, that leave out local knowledge as well as a large number of actors in the cluster, contributing to the existing high social and economic inequality. This is the case in the sugarcane cluster of Veracruz. In this context, the main objective of the article is to show that in this type of reality, the modernization of the cluster and the generation of new networks of innovation that integrate local resources and knowledge as well as potential endogenous requires, as a precondition, the generation of social innovation. In order to meet this objective, an evolutionary theoretical framework is developed, explaining both the inertia as well as the forces of change, combined with other approaches that address the phenomena of power and social innovation. This theoretical framework will try to show how the values of the social economy can be the vehicle of social innovation and the engine of change in the cluster, through the generation of novelties in itself. These novelties come from the emergence of new actors, new skills, new relationships and new rules. Based on this theoretical framework and in line with the interest of this article for the knowledge of the processes and the forces that move them, qualitative research has been developed in the sugarcane cluster of Veracruz (Mexico). This research relies primarily on the realization of almost a hundred in-depth personal interviews conducted in 2017 and 2018, with companies in the value chain, various associations, training and research centers as well as experts in the sector. The sample of companies has sought to privilege the presence of the sugar mills and a group of new dynamic firms, and for different reasons: in the first place, for its central role in the organization of the cluster which we aim to understand and, in the second place, due to its transformational potential.

It has been shown that in the sugarcane cluster of Veracruz, the value chain organization exhibits an important vertical integration in the hands of sugar mills, and whose correlation is the concentration of most of the public research efforts around the innovation network of these sugar mills. On the other hand, some local actors and knowledge are marginalized and with little communication between them, with the problem of fragmentation of knowledge and lack of penetration of new sources of information and innovation that this implies. Also, it has been shown that the essential question is, that behind this productive concentration there are a series of political and business networks, which in addition to ensuring the interests of the participating groups are extending a set of values that feed violence and discrimination. In this context, the mobilization of dispersed and already existing resources 


\section{LOS VALORES DE LA ECONOMÍA SOCIAL COMO IMPULSORES DEL CAMBIO EN CLÚSTERES CON FUERTE FRAGMENTACIÓN DEL CONOCIMIENTO: EL CASO DE LA CAÑA DE AZÚCAR DE VERACRUZ (MÉXICO)}

on which development depends (Hirschman, 1961), as a basis for deploying own trajectories that allow escape from external economic and technological dependence (Prebisch, 1981), it involves an exercise for the development of people's capacities, putting the emphasis on human development (Sen, 2000).

In this sense, the article shows how social economy can contribute to the transformation of Latin American clusters through their moral rearmament that places people at the centre of political concerns and scientific analysis. Within the framework of the dominant political-economic network, it was shown how the creation of formal cooperatives cannot play, either alone or through the second-degree management and cooperative teams, the transforming role of the clusters which was attributed to it by the literature in other clusters of developed regions (Gallego-Bono \& Chaves-Ávila, 2015 and 2016). The reason is that in this framework, the cooperatives are captured and used spuriously by this network. However, the article shows that the values of the social economy can constitute a vehicle to mobilize the endogenous resources communicating with their values and behavioural patterns, an actual alternative project of society. This project is making its way through the development of a series of socially emancipatory business and associative initiatives that are inspired and promote responsibility, social capital and a new, more inclusive vision of business activity while mobilizing local resources. These are individual and collective initiatives that encourage new forms of organization and greater productive diversification, which introduce more substantial complexity in the value chain, to extend and take advantage of endogenous knowledge, but based on the mobilization of critical external connections.

New actors are detected that no longer pursue the use of resources supported by imports, external demand for technology and agricultural sciences. These are young entrepreneurs endowed with high skills and new values, leading them to turn their attention to human resources, intellectual capital and endogenous capacities of the territory. In other words, towards the use of resources that were mostly there, but that due to differences in values and power between the actors involved, they were not noticed until very recently. This implies the valorization of a part of the local knowledge collection, part of a tacit nature, in terms of agricultural production, industrial transformation, etc. A use of local knowledge that serves as a basis for the intensification of the division of labour and specialization in the value chain, as well as the improvement of external sector-based and spatial connections in addition to the opening of new markets.

One of the main limitations of this research is that it focuses on a single case study. Still, the problem it describes is considered, in particular, the framework of economic-political power and its main external links through the North American Free Trade Agreement (NAFTA) to be extensible to other Mexican agri-food clusters. It is suggesting, on the other hand, an essential line of future research.

The fundamental contribution of this work consists in developing, conceptually and empirically, a feasible way to integrate endogenous resources into innovation processes within the framework of clusters of developing countries, especially in Latin America, and to change the habit or tendency to disap- 
prove and exclude them which predominates among themselves. So all this through the practice of the human values of inclusion, participation and equity that promotes social innovation and the social economy as a privileged vehicle for itself, not with a moralizing purpose, but with a practical mission of good governance and transparency as "vectors" of innovation. The article contributes some crucial details to the existing literature on clusters as well as social and technological innovation. In the first place, in the face of writing that highlights the lack of cooperation in Latin American clusters (Rocha, 2015), it is evident that the fundamental problem is not in here, but in a socially exclusive partnership. Secondly, it is evident that in this type of clusters social innovation is a condition of technological innovation. A social innovation that has a marked radical character (Marques et al, 2018) more for the depth and vision of the world and the values that inform it, than for the real challenge in the established powers. Thirdly, it has been shown that the stimulus to change cannot come from cooperative initiatives but from the broader values of democracy, participation and commitment with the community that distil the set of social economy initiatives (Chaves and Monzón, 2018). The picture emerges, both theoretically and empirically, of the possibility of new individual and collective business initiatives bearing new values and new internal and external relationships capable of introducing variety into the territorial system. These actors are driving a new logic of integration of knowledge in the cluster, along with an advancement in the division of labour and the generation of organizational, product and market innovations within the cluster and the value chain.

In terms of economic policy, it is inferred from the article that in order to carry out actions capable of overcoming the fragmentation of knowledge in these types of clusters, policies should generate spaces of confluence of interests of the innovation networks, while promoting participatory and inclusive governance based on the transparency of the institutions. In the type of cluster considered, supporting their values is more important than prioritizing the legal formulas of the social economy.

KEYWORDS: Fragmentation of knowledge, Discrimination, Social economy, Social innovation, Cooperative values, Sugarcane, México. 


\section{LOS VALORES DE LA ECONOMÍA SOCIAL COMO IMPULSORES DEL CAMBIO EN CLÚSTERES CON FUERTE FRAGMENTACIÓN DEL CONOCIMIENTO: EL CASO DE LA CAÑA DE AZÚCAR DE VERACRUZ (MÉXICO)}

\section{Introducción 1}

El presente artículo analiza la dinámica del clúster de la caña de azúcar de Veracruz (México). Siguiendo la definición de Porter (1998:78), este clúster viene delimitado por la concentración en una zona de empresas e instituciones de apoyo a esta actividad. Y se supone que un clúster va más allá de una aglomeración de empresas, en el sentido de que éstas han de mostrar un cierto grado de relación entre las mismas (Van Dijk y Sverrisson, 2003). Además, la literatura habla de un sistema territorial de producción y de innovación (en adelante STPI) cuando tanto las relaciones entre empresas como entre empresas, universidades y centros tecnológicos y de investigación, dentro de un sector 0 de un conjunto de sectores, son muy densas e incluyen además una importante dimensión formal (Cooke et al 1998; Cooke, 2001). En nuestro caso, estamos en presencia de un clúster que ha dado algunos pasos para devenir un STPI dentro del ámbito de la caña de azúcar, pero que muestra muchas tensiones para recorrer este camino entre otras razones porque no incorpora el conocimiento de base local. En este sentido, el artículo trata de evidenciar el papel de los valores de la economía social como impulsores del cambio en la dirección de propiciar un desarrollo local más sostenible y basado en el conocimiento endógeno. La producción de caña de azúcar es el motor económico de esta región del centro de Veracruz. Y, de hecho, en las últimas décadas han aumentado continuamente el precio del azúcar, la superficie cultivada y la producción industrial. Sin embargo, la descomposición social de la región ha sido todavía más rápida, lo que ha llevado a un aumento de la violencia y de la exclusión social. A este problema ha contribuido una organización del clúster que fragmenta el conocimiento, propicia la discriminación y no estimula la innovación en el mismo.

Se intentará mostrar cómo los problemas de fragmentación del conocimiento y de reducido dinamismo innovador en el clúster de la caña de azúcar de Veracruz tienen su origen en la fuerte integración vertical y el carácter restringido de las relaciones de confianza que padecen con frecuencia los clústeres en América Latina (Van Dijk \& Sverrisson, 2003:191), existente también en el sector de la caña de azúcar. Problemas a los que añadiremos el escaso fomento de la participación y la falta de transparencia y compromiso por el trabajo colectivo. Las propias políticas públicas carecen de planeación (Lewis, 2004) y son con frecuencia un vehículo del cohecho y de legitimación de las élites en el poder.

En este marco, como así lo evidencian varios productores de caña y de otros cultivos entrevistados, la creación de cooperativas agrícolas constituye una fórmula empresarial colectiva que se ha adulterado, convirtiéndose en un instrumento para desviar dinero, de promoción del voto cautivo y del clientelismo (Comunicaciones personales, 2017 y 2018).

1.- Los autores agradecen las interesantes sugerencias de dos evaluadores anónimos que han permitido mejorar la calidad del artículo, aunque nosotros somos los únicos responsables del resultado final. El artículo se beneficia del proyecto de investigación GOBEFTER II) (CSO201678169-R), del Plan Estatal de Investigación Científica y Técnica y de Innovación. 
Los problemas se complican cuando los empresarios en la región se muestran propensos a imitar de forma acrítica las innovaciones de base científico-tecnológica de carácter exógeno y las centradas casi exclusivamente en la investigación en materia de producción agrícola. Esto conduce a minusvalorar otras formas de conocimiento que se encuentran en el territorio y cuyo aprovechamiento fortalecería los procesos de inclusión, confianza, consulta, trabajo en red y participación de los actores implicados, al tiempo que permitiría a los actores locales impulsar la mejora de su propia calidad de vida.

Con algunas excepciones, la literatura actual sobre innovación social (Parra, 2013; Van Dyck \& Van den Broeck, 2013; Lévesque y Lajeunesse-Crevier, 2005) se ha desarrollado de forma bastante independiente de la investigación sobre clúster y sobre innovación y sistemas de innovación (Lundvall, 2010; Dahlman, 2007; Ebner, 2010). Frente a toda esta literatura, el presente artículo tratará de evidenciar que en el marco de un clúster en regiones en desarrollo y en sectores tradicionales, la innovación social constituye una precondición para el reconocimiento y el avance hacia un STPI que ponga en valor las capacidades y los conocimientos locales, en especial los basados en la experiencia. Y ello como base para la superación de los procesos de fragmentación del conocimiento (Gallego-Bono, 2016), y de estímulo al desarrollo de nuevas formas de organización y de innovación en el clúster. En efecto, la innovación social constituye el camino a través del cual aparecen en escena nuevos actores, nuevas competencias (Nooteboom, 2010), nuevas capacidades (Sen, 2000) y nuevas relaciones (Portes, 2006) que son claves en los procesos de cambio (Nelson \& Winter, 1982; Nelson, 2016).

Una parte de la literatura sobre clústeres en regiones desarrolladas, ha puesto el énfasis en la capacidad de las cooperativas, y sus estructuras asociativas y de segundo grado, para impulsar el emprendimiento colectivo (Gallego-Bono \& Chaves-Ávila, 2015), así como el papel mitigador (gracias a los valores cooperativos) que juegan las cooperativas de los posibles desequilibrios que se generan en los clústeres con los procesos de innovación tecnológica (Gallego-Bono \& Chaves-Ávila, 2016). Profundizando en esta última línea de investigación, en este artículo se adopta una perspectiva más general y se destaca la importancia de la economía social (en adelante, ES) en una nueva dimensión, en el marco de clústeres en regiones y países en desarrollo. Se trata de la posible condición de los valores de la ES de palanca o desencadenante del cambio inicial en los clústeres. En efecto, a partir del desarrollo esencialmente espontáneo de los principios de la ES, se desarrolla la innovación social que constituye el vehículo de nuevas formas de considerar los conocimientos locales y de modificación de las actividades y organización de la cadena de valor en el sector y en el clúster.

Se tratará de evidenciar en definitiva, que los valores de la economía social constituyen una palanca para la movilización de los recursos dispersos, no utilizados y ya existentes de la que depende el desarrollo (Hirschman, 1961:17).Y ello como base para desplegar trayectorias propias de desarrollo que permitan escapar de la dependencia económica y tecnológica externa (Prebisch, 1981), lo que comporta un ejercicio para aumentar las capacidades de las personas y poner el énfasis en el desarrollo humano (Sen, 2000). Para tal fin es importante comprender que la innovación es un proceso cultural que se difunde y acelera con la aceptación social selectiva y la integración (Ferrer, 2013; Steiner \& 


\section{LOS VALORES DE LA ECONOMÍA SOCIAL COMO IMPULSORES DEL CAMBIO EN CLÚSTERES CON FUERTE FRAGMENTACIÓN DEL CONOCIMIENTO: EL CASO DE LA CAÑA DE AZÚCAR DE VERACRUZ (MÉXICO)}

Hartmann, 2006) por lo que, en la planeación estratégica de una empresa o una política pública, es importante adoptar valores compatibles con el desarrollo humano. Por tanto, resulta esencial la Innovación Social para la conformación de redes de actores empresariales e institucionales (centros de investigación, universidades, etc.) con una diferente visión del mundo, que entronquen y que sean portadores de los referidos valores y los beneficios del aprendizaje en grupo para contener la desintegración social.

El objetivo de este artículo es mostrar que la identidad (propósito) que confieren los valores y principios de la ES a una serie de actores críticos con el statu quo, pero comprometidos con el clúster, unifica la dirección de las acciones (visión) y promueve la conciencia (reflexión) colectiva para abordar los problemas comunes con un enfoque integrador, inclusivo y sostenible.

Para tratar de lograr el objetivo perseguido, el artículo se estructura como sigue. En la siguiente sección se esboza un marco teórico evolucionista donde se trata de integrar de forma original una problemática de poder y de fragmentación/integración del conocimiento con un enfoque de innovación social. Después se utiliza este marco conceptual para intentar ofrecer una nueva luz sobre la organización y dinámica del clúster de la caña de azúcar de Veracruz (México), todo ello sobre la base de una investigación cualitativa apoyada en la realización de entrevistas en profundidad. El artículo se cierra con unas conclusiones.

\section{Los valores de la economía social como motor de cambio en los clústeres de países en desarrollo}

2.1. La dialéctica fragmentación/integración del conocimiento como vector de inercia/cambio de los clústeres

Hasta el presente se ha desarrollado una vasta literatura sobre clústeres y STPI que ha prestado escasa atención al poder y al Estado (Van Dick \& Van der Broeck, 2013; Markusen, 1999; FernándezSatto \& Vigil-Greco, 2007), al tiempo que dejaba de lado la dialéctica existente entre las relaciones de confianza y de poder en los clústeres y STPI (Gallego-Bono \& Lamanthe, 2009). Por eso, se da la aparente paradoja de que la literatura sobre clúster y STPI han prestado mucha atención a las instituciones y a las políticas públicas (Lundvall, 2010; Asheim \& Coenen, 2005; Cooke \& Morgan, 1999; Hannan \& Freeman, 1977), pero muy poca al poder. Y, sobre todo, no se ha tenido en cuenta la necesidad de insertarlo en el marco de las políticas de estado de los clústeres de América Latina (en adelante, $\mathrm{AL}$ ) (Fernández-Satto \& Vigil- Greco, 2007). En otros términos, una primera idea que se sostiene es la necesidad de conectar los fenómenos de poder en una conceptualización de los clústeres y STPI en países en desarrollo, a las propias actuaciones del Estado. Esta importancia del poder y del Estado resulta 
esencial para conceptualizar la fragmentación del conocimiento que predomina con frecuencia en los clústeres y STPI de AL. Pero antes se impone analizar la fragmentación en términos más generales.

En efecto, la literatura sobre clústeres y STPI se ha centrado habitualmente en los casos de éxito y ha ofrecido una visión de los mismos como desprovista de tensiones, casi siempre poniendo el foco en la importancia de la confianza y la cooperación en las relaciones entre actores (Martin \& Sunley, 2003). Ahora bien, un primer paso para matizar este planteamiento, lo proporciona una literatura que defiende que las relaciones entre actores de los clústeres y STPI no son tan fluidas y generales, porque son en gran medida selectivas (Tomás Carpi, et al., 1999; Van Dijk \& Sverrisson, 2003; Giuliani, 2007; Molina-Morales et al, 2012). Así, los actores tienden a relacionarse únicamente o preferentemente con aquellos con los que comparten una serie de referencias sociales, en términos de conocimiento comunes (Phelps et al, 2012; Grossetti \& Bès, 2001; Torre, 2006) y de valores, para organizarse colectivamente y defender determinadas perspectivas o trayectorias de desarrollo del conocimiento y de la innovación (Belussi \& Sedita, 2012; Gallego-Bono, 2016). En muchos casos, además, estos procesos tienen lugar cuando dichos clústeres se internan en el desarrollo de redes de innovación (en la transición hacia STPI), que no solo incluyen el conocimiento por la experiencia, sino que también incorporan al conocimiento científico-tecnológico más sistemático. Sin embargo, este juego político (de lucha entre actores) y la consiguiente tendencia a la fragmentación de las redes de innovación, tiene su reverso positivo. Sí, se trata de la posibilidad de definir nuevos espacios más ricos, complejos y diversos de conocimiento y de innovación cuando los actores son capaces de poner en común y de acordar diversas perspectivas para crear redes de actores y de innovación más amplias. De ahí, el que pueda hablarse de una dialéctica fragmentación/integración de las redes de innovación asociada al desarrollo del conocimiento y de la innovación en los clústeres y STPI (Gallego-Bono, 2016). A veces el problema en los clústeres en regiones en desarrollo para que se genere esta dinámica de integración, radica en la falta de incentivos a la cooperación a largo plazo, por ejemplo, en la forma del establecimiento de redes estables de cooperación usuario/productor de maquinaria destacada por Van Dijk y Sverrisson (2003:197). Se bloquearía así un proceso de mayor división del trabajo, especialización y cooperación en el clúster.

No obstante, para dar cuenta de la problemática de AL es necesario incorporar dos elementos importantes, cuales son: a) la debilidad empresarial que afecta a muchos clústeres en países en desarrollo (Gorenstein y Moltoni, 2011:78) y b) la corrupción, que afecta a las instituciones y a la actividad empresarial establecida (Robinson, 2012), así como el papel de los valores, clave para comprender las sociedades de AL.

Nuestra hipótesis es que la conexión entre los valores, de un lado, y el sistema de producción y de innovación, de otro, opera esencialmente a través del papel del empresario. A través de su visión, éste va a tener una función esencial en la creación e impulso del conocimiento y, por consiguiente, en las nuevas prácticas y modelos de relaciones. El empresario juega un papel fundamental en la coordinación de las personas que integran una empresa y que tienen intereses, competencias y valores con frecuencia diferentes (Witt, 1998, Tranos, 2014); y el mismo argumento se puede generalizar en 


\section{LOS VALORES DE LA ECONOMÍA SOCIAL COMO IMPULSORES DEL CAMBIO EN CLÚSTERES CON FUERTE FRAGMENTACIÓN DEL CONOCIMIENTO: EL CASO DE LA CAÑA DE AZÚCAR DE VERACRUZ (MÉXICO)}

términos de personas y organizaciones que asumen en el territorio un liderazgo socio-económico colectivo, aunque no sean entidades empresariales. Siempre se trata de lanzar un proyecto con capacidad de cohesionar a actores diferentes (Witt, 1998; Gallego \& Pitxer, 2012). El emprendimiento puede jugar un papel esencial como vehículo de la innovación (Bas et al, 2008). Ahora bien, es necesario tener en cuenta que la función empresarial puede constituir también el problema, cuando el elemento vertebrador de la visión es precisamente preservar el poder establecido. Esto puede contribuir a que se instauren en la sociedad una serie de valores generales que lejos de regular las posibles tensiones, a menudo asociadas a los cambios tecnológicos, organizativos, cognitivos y comportamentales (Dopfer y Potts, 2008; Cooke, 2014; Gallego-Bono y Chaves-Ávila, 2016), tengan en realidad el efecto de inhibir dichos cambios.

En esta dirección, una práctica habitual en AL ha sido apostar por tecnologías importadas que son difícilmente asumibles por las sociedades regionales, y que condenan a estos países a seguir trayectorias de desarrollo dependientes del exterior, poco coherentes con su dotación de recursos (Prebisch, 1981; Rocha, 2015) y sus capacidades. En este sentido, aquí se sostiene la idea de que el sesgo hacia el conocimiento científico y formal que promueven las instituciones y los actores centrales de estos clústeres, constituye un factor explicativo clave de la fragmentación de las redes de innovación y de conocimiento de los STPI. La razón es que muchas veces margina al conocimiento de base endógena y a los actores en posesión del mismo. De este modo, en regiones en desarrollo resulta esencial, más que en ninguna otra parte, superar una noción restringida de sistema de innovación que únicamente abarca las instituciones y redes de innovación centradas en la ciencia y en el aprendizaje sistemático y codificado. Por tanto, hay que dar paso a una definición amplia que incluya el aprendizaje basado en la experiencia y en el conocimiento tácito (Lundvall et al 2010; Chaminade et al, 2018).

Con esta definición amplia de innovación y de sistema de innovación, se afirma la importancia práctica de los factores socio-culturales en las actividades de innovación y difusión del conocimiento (Capello \& Faggiani 2005), esto es, el saber hacer, las costumbres, las tradiciones, los valores y las maneras de comunicar/silenciar el conocimiento popular. Pero este paso, si bien supone un progreso en la concepción dinámica de la economía y los clústeres en particular, resulta insuficiente. En efecto, no se ha comprendido que, subyaciendo a esta fragmentación del conocimiento, se_encuentra en parte la escasa atención prestada a los saberes y los recursos locales, y al conocimiento tácito por la experiencia. Este olvido, ha alimentado los problemas de marginación y discriminación que se han forjado histórica y culturalmente en estas latitudes hasta convertirse en un problema socio-económico habitual. El recurso a la discriminación es importante para comprender que, dentro de numerosos clústeres de $A L$, este problema necesita ser reconocido para dejar de proteger de forma sistemática y organizada la predisposición a las relaciones selectivas entre los actores (Roldán et al, 2018) y para conocer el origen y razón de ser de la continuidad de esta fragmentación del conocimiento. La cuestión clave radica en que en muchos clústeres de AL la función empresarial explica varios vectores (de lucha y de negociación) definitorios de las redes de innovación, generadores de una fragmentación radical que frena su desarrollo. En efecto, la selección de las relaciones y las luchas entre grupos organizados por un tipo de perspectiva y/o disciplina científica, o forma de entender cuál debe ser el desarrollo del cono- 
cimiento y de la innovación (Cooke, 2014; Belussi y Sedita, 2012; Gallego-Bono, 2016; Hildreth \& Kimble, 2004), pierde aquí importancia en favor de otros elementos como la captura de los recursos a través de coaliciones público-privadas. En suma, estas coaliciones que sostienen a las redes de innovación, no responden tanto a la lucha organizada en pro de un tipo de idea y de conocimiento como instrumento de poder, sino a una organización para apropiarse de los recursos. Y esta captura de recursos por una élite constituye una fuente esencial de marginación y de discriminación social y económica, al privar a buena parte de los actores del clúster del acceso a estos recursos. Es pues vital comprender la colaboración entre las élites empresariales y el Estado, en la organización y dinámica de los clústeres.

El conocimiento científico-tecnológico se dirige a los sectores de la economía que son señalados como estratégicos por el gobierno. En palabras de Cabra de Luna (2012), las políticas públicas son herramientas de presión y manipulación. Quienes planean y ejecutan las políticas públicas tienen aversión al conflicto y al cambio y no aceptan la "destrucción creativa" como parte del proceso del desarrollo y la innovación, ni como una oportunidad de crecimiento y mejora. Continuando con la exploración de las políticas de "desarrollo", Vick (1998) indica que en AL, estas suelen ser acciones de ayuda, asistenciales, de corto plazo, paliativas, desarticuladas, espontáneas y/o promocionales, lo que incentiva a los receptores a ser pasivos y a pensar en sí mismos como incompetentes. En esta misma línea, Katz y Stumpo (2001), afirman que el desarrollo en AL fue fomentado por políticas gubernamentales dirigidas, que no promueven el conocimiento ni el mercado interno, y sí los monopolios, la extracción de recursos y la inversión extranjera directa. Estos últimos autores indican, del mismo modo, que se desatienden las aportaciones de la cultura local o la idiosincrasia. Incluso los usos y costumbres son percibidos como obstáculos para el progreso y no se otorga la importancia necesaria a las ventajas de la proximidad geográfica y del capital social. Con esto se concluye que la práctica de las políticas públicas favorece repetidamente a los grupos de actores más poderosos políticamente. En contraste con estas coaliciones de poder, las empresas regionales, generalmente especializadas en un área de producción-conocimiento, podrían jugar un rol fundamental como puentes que permitan alcanzar fuentes externas y complementarias de conocimiento para cubrir los agujeros estructurales en el territorio (Florida, 2014; Schiuma \& Lerro, 2008). Pero esto requiere que las empresas locales estén imbuidas de nuevos valores y tengan la capacidad necesaria.

\subsection{De las instituciones formales de la economía social a sus valores como motor del cambio}

Desde una perspectiva evolucionista, la riqueza de las naciones reside en la mente humana y su propensión a originar, adoptar y retener nuevas ideas. La novedad es el origen de toda riqueza. "Se requiere libertad individual y coordinación social para originar, adoptar y retener la novedad que hace crecer las oportunidades y la riqueza" (Dopfer \& Potts, 2008, pág. 13). No obstante, en un marco institucional dominado por la concentración de poder político y económico en una minoría, y por el predominio de unos valores que los legitiman y/o que propician la inacción de la mayoría de la población, 


\section{LOS VALORES DE LA ECONOMÍA SOCIAL COMO IMPULSORES DEL CAMBIO EN CLÚSTERES CON FUERTE FRAGMENTACIÓN DEL CONOCIMIENTO: EL CASO DE LA CAÑA DE AZÚCAR DE VERACRUZ (MÉXICO)}

en un contexto de miedo y de violencia, las posibilidades de promoción de la ES con políticas públicas son muy limitadas. En efecto, cabe esperar que, en este marco, incluso una política decidida de estímulo legislativo al desarrollo de las fórmulas jurídicas o instituciones formales de la ES, puedan conducir en la realidad a una captura de los recursos con los que se trata de incentivar la ES. Es lógico a este respecto, anticipar con cierta probabilidad la captación de rentas (económicas y relacionales) por parte de las coaliciones de actores más poderosos. Por tanto, es cierto que las instituciones formales (leyes, etc.) son las responsables de proporcionar el marco legal básico en el que se desarrollan las actividades socio-económicas, y son las encargadas en primera instancia de proporcionar el orden y la continuidad que favorecen el desarrollo y la innovación. No obstante, esto no es suficiente para garantizar la honestidad y la transparencia necesaria para que pueda haber confianza entre los agentes en el mercado, cuando las relaciones de poder y los valores están muy sesgados hacia los intereses de unos pocos.

Otra posibilidad de innovación podría venir por la vía del impulso del cambio meso, esto es, en las rutinas tecnológicas, cognitivas, comportamentales y sociales del conjunto de empresas u otras entidades que forman parte de una población determinada (Dopfer \& Potts, 2008). En efecto, se ha evidenciado que las cooperativas constituyen una herramienta para potenciar innovaciones de alcance meso, a través de las presiones al cambio y de la ayuda a la mejora de sus miembros que suponen sus estructuras de primer y segundo grado (Gallego-Bono \& Chaves-Ávila, 2015). Sin embargo, esta posibilidad no parece factible cuando la creación de las cooperativas obedece a motivos espurios, conforme al análisis avanzado. Por la misma razón, resulta menos lógico esperar que el detonante de la transformación pueda proceder del impulso al cambio de valores en el clúster promovido por las pro-

pias cooperativas (Gallego-Bono \& Chaves-Ávila, 2016), y otras entidades de la economía social ya consolidadas, debido a la escasa probabilidad de que existan organizaciones de esta naturaleza con arraigo a los principios y valores de la economía social. Ahora bien, el que las políticas públicas, las fórmulas jurídicas de la ES (y en particular las cooperativas) y las estructuras directivas de las cooperativas presenten serias limitaciones para definir una vía de cambio en este tipo de clústeres de AL, no quiere decir que no puedan existir fuerzas a su favor.

En efecto, la tesis que aquí se sostiene es que en los clústeres de países en desarrollo de $\mathrm{AL}$, envueltos en la problemática socio-política-económica descrita, la ES podría jugar un papel esencial como motor del cambio, pero a través de la propia asunción por una parte creciente de los actores del territorio de los valores y principios de funcionamiento que destilan las entidades que conforman la ES. Para valorar mejor cómo pueden los valores de la ES operar este cambio es necesario precisar su naturaleza.

En primer lugar, hay que tener en cuenta que está apareciendo una definición dinámica de economía social que va más allá de sus formas clásicas (cooperativas, mutuas, asociaciones y fundaciones), para hacerse eco de "las nuevas formas que tratan de dar respuesta a necesidades no cubiertas por el mercado o el Estado" (Chaves y Monzón, 2018:14). En segundo lugar, que "la ES destaca por subrayar los valores democráticos, participativos y de orientación y propósito social" (Chaves 
y Monzón, 2018:14). Y, en tercer lugar, en todas las entidades de la ES estos principios y valores sostienen "formas organizativas atendiendo a tres criterios: el objetivo de la organización, el modo de decisión y el modo de distribución de los beneficios y excedentes que genera esta entidad" (Chaves y Monzón, 2018:14). Esto evidencia la conexión potencial entre los valores de la ES y la transformación del sistema productivo.

En este marco, el primer paso para que puedan operar los valores como fuente de cambio es, pues, que estén relativamente asentados entre una parte de la población del clúster, una forma de gobernanza (tipo de coordinación entre actores y de toma de decisiones colectivas) transparente y participativa, y unos valores y principios como los que defienden las cooperativas 0 , más en general, las entidades que conforman la ES. Únicamente superado este umbral, es cuando podrán operar los mecanismos de impulso al cambio y a la modernización de los clústeres contemplados más arriba. En otros términos, la ES dirigida intencionadamente como proceso socio-cultural (de cambio en los valores y la cultura), puede tener un importante efecto sobre el desarrollo regional en su conjunto (Lévesque \& Lajeunesse-Crevier, 2005; Giovannini, 2012). Ahora bien, para que este proceso desde arriba sea factible, es necesario que los actores defiendan y asuman previamente como propios, aunque sea de manera inconsciente o no intencional, los valores de la ES.

La ES, y de forma más particular las cooperativas, difunde los valores de auto-ayuda, responsabilidad, democracia, igualdad, equidad y solidaridad; además de virtudes como la honestidad, la empatía, la cooperación y el respeto hacia los demás. Al priorizar a las personas sobre el capital, la ES pone el énfasis en los valores humanos, pero también en un tipo de visión particular que liga los valores humanos a la función empresarial. Una articulación entre valores humanos y empresa que propone nuevas relaciones sociales y nuevas formas de resolución de necesidades hasta entonces no cubiertas, que nos conduce a una problemática de innovación social (Moulaert et al, 2013; Marques et al, 2018). Y también hacia la modificación de la actual gobernanza jerárquica y discriminatoria.

Efectivamente, desde la perspectiva de la Nueva Economía Social, la identificación, integración, difusión y conexión de los valores humanos con la empresa, se consiguen a través de la ES (Lévesque, 1999), dado que las innovaciones sociales están invariablemente presentes en el desarrollo económico (Alburquerque, 2006). Esto se explica porque los valores humanos, junto con las actitudes y los conocimientos, son "transmisores y engranajes" del sistema económico en el entorno humano y social donde funcionan. "Son generadores de capital humano, impulsores de la capacidad creativa, cauces del aprendizaje colectivo y articulador de redes sociales” (Tomás Carpi, 2008, págs. 78-79).

A través de la aplicación de los principios y valores de la ES, se puede facilitar el ejercicio de estas capacidades para el desarrollo sostenible de un clúster o un territorio. Se entiende que no puede haber desarrollo y evolución económicos, si no se tiene en cuenta la corrección de las condiciones sociales de desigualdad y exclusión social (OCDE, 2001). Pero con frecuencia, se ha prestado poca atención a la posible relación directa e indirecta de las innovaciones científicas y tecnológicas con el deterioro del ambiente y la desintegración social (Marques et al, 2018). La entrada de los principios 


\section{LOS VALORES DE LA ECONOMÍA SOCIAL COMO IMPULSORES DEL CAMBIO EN CLÚSTERES CON FUERTE FRAGMENTACIÓN DEL CONOCIMIENTO: EL CASO DE LA CAÑA DE AZÚCAR DE VERACRUZ (MÉXICO)}

y valores de la ES en la comunidad y el territorio ayudan a tomar conciencia de los problemas colectivos, a marcar objetivos definidos para alcanzar su prosperidad (desarrollo sostenible) y a cambiar las reglas, los hábitos y las normas de conducta de la actual gobernanza excluyente. Igualmente, contribuye a anteponer los derechos del grupo a los del individuo y también a controlar algunos de los desequilibrios sociales causados por el crecimiento económico acelerado (Cabra de Luna 2012). Y a esto último, cabe añadir que los valores también pueden ayudar a reducir el desfase entre el rápido crecimiento económico y la mayor lentitud con la que se desarrollan las nuevas competencias necesarias para adquirir y mantener el bienestar social de la población.

En amplias zonas de AL, se asiste en las últimas décadas a la desintegración social causada por la desigualdad de oportunidades y la discriminación (Roldán et al 2018). Particularmente, México se encuentra entre los diez países del mundo con mayor desigualdad (Acciona, 2019), y de acuerdo con el informe de Transparencia Internacional, México, con 29 puntos, se ubicó en el lugar 138 de 180 países en términos de corrupción (Televisa 2019).

Hermanadas con la globalización, por las presiones del libre mercado y por los valores superficiales transmitidos por los medios de comunicación masiva como agentes externos (Giddens, 2003), todas estas transformaciones componen un panorama que revela la necesidad de apurar el proceso de innovación social. Se trata no solamente de identificar los valores humanos que propugna la ES y que ya existen al menos en germen en el propio clúster, sino también de potenciarlos e intentar extenderlos (Montes, 2012) aplicando las diferentes clases de conocimiento, y promoviendo otros tipos de actividades, modelos de negocios y de industrias con las capacidades ya existentes en la región (Tödling \& Trippl 2018). La ES, no afecta o compete únicamente al desarrollo del sistema económico, sino también al desarrollo del sistema social y, en consecuencia, a la estabilidad del sistema medio ambiental.

Gracias a la ética de la ES, en tanto valores humanos que operan como transmisores de incitación y de responsabilidad individual y colectiva, resulta posible cambiar las reglas y normas de conducta de la gobernanza actual y se tiene la oportunidad de establecer un foro para fomentar la integración, el deseo de colaboración y la confianza. Cuando se abre paso la utilización de estos valores, diferentes a los que prevalecen actualmente, ello puede hacer retroceder la demagogia y empujar hacia un proceso de transformación de las instituciones formales en favor de los actores marginales del clúster. Con esto, los integrantes logran descubrir nuevos espacios de interacción, se incrementa la capacidad de absorción del conocimiento por parte de los actores marginales, y la capacidad de integración de los diferentes tipos de conocimiento.

En suma, este artículo sobre los clústeres y STPI en regiones en desarrollo (en particular de AL) propone fijar la atención en los principios y valores de la ES, como vehículo para comprender y propiciar simultáneamente una mayor participación de las minorías en la toma de decisiones, el desarrollo de una función empresarial crítica con el statu quo, y la creación de nuevas reglas y hábitos para la resolución de problemas comunes. Con esto se consigue promover al propio tiempo el interés, el 
aprendizaje y el compromiso cívico con una gobernanza más transparente y participativa. El enfoque de la ES fomenta la promoción de capacidades para la participación, la construcción de tejido social, la resolución de conflictos, la cultura de paz y la promoción de la justicia social dentro del sistema económico y social en AL (Cabra de Luna, 2012).

\section{Metodología y fuentes de información}

En coherencia con una preocupación por desentrañar los aspectos cualitativos y dinámicos del clúster de la caña de azúcar en Veracruz, el artículo se ha apoyado en una metodología cualitativa de investigación empírica que se basa sobre todo en la realización de visitas de campo y entrevistas personales en profundidad. Dichas entrevistas se realizaron en 2017 y 2018 a dos tipos de actores. Por una parte, a empresas de los diferentes eslabones de la cadena de valor $y$, por otra, a testigos privilegiados (funcionarios públicos, académicos y directivos de universidades y centros de investigación y de formación, así como directivos de asociaciones técnicas y empresariales). Las entrevistas a todos los actores anteriores fueron realizadas con un cuestionario cerrado. Ahora bien, a una parte de los expertos que tenían una visión de conjunto del clúster se les formuló también una serie de preguntas abiertas.

Se han realizado un total de noventa y cinco entrevistas: cincuenta y siete con los actores involucrados en la cadena de valor y treinta y ocho con testigos privilegiados. Aunque la muestra incorpora un número importante de empresas, no ha podido ser mayor a tenor de la complejidad de la red de relaciones que conforman el clúster cañero en la región y de la dificultad de acceso a las empresas debido al clima de violencia y de inseguridad que padece la zona en los años recientes. Las entrevistas tenían entre una hora y media y dos horas y media de duración, y han sido grabadas en un audio. Las respuestas a las entrevistas realizadas con cuestionario cerrado han sido procesadas y sistematizadas para su presentación en forma de tablas. Las respuestas a las entrevistas realizadas con cuestionario abierto han sido objeto de un análisis de textos para captar las asociaciones y cuestiones más relevantes. Las visitas de campo fueron realizadas a las plantas de fabricación industrial (azúcar) y artesana (piloncillo) de la caña de azúcar. De igual forma, se visitó el área de plantación durante las etapas de cultivo y de cosecha.

La confección de la muestra no es estadísticamente aleatoria porque buscaba captar la tensión entre inmovilismo y cambio. Por eso, aunque se ha tratado de recoger en la misma a todos los eslabones de la cadena de valor, se ha discriminado positivamente la presencia en la misma de los ingenios porque eran considerados un actor clave para comprender la organización del clúster. De igual modo, la muestra también presenta un nutrido grupo de firmas innovadoras (piloncilleros, proveedores, etc.), porque se detectó en el clúster un conjunto de empresas PYMES que respondían a la ini- 


\section{LOS VALORES DE LA ECONOMÍA SOCIAL COMO IMPULSORES DEL CAMBIO EN CLÚSTERES CON FUERTE FRAGMENTACIÓN DEL CONOCIMIENTO: EL CASO DE LA CAÑA DE AZÚCAR DE VERACRUZ (MÉXICO)}

ciativa de personas que se apartaban de la norma en términos de valores y redes de relaciones e influencias (internas y externas), además de ser más jóvenes y/o de tener elevados niveles de formación. Además, estos emprendedores introducían no solo innovaciones de producto o de mercado, sino también auténticas innovaciones sociales. Al estudiarlos sistemáticamente como grupo a partir de los resultados de algunas primeras entrevistas, ha sido posible detectar otras especificidades sobre las que se incidirá posteriormente. Ahora bien, la aleatoriedad de la muestra proviene de que la mayoría de empresas han sido proporcionadas por informantes clave y buenos conocedores de la región a partir de las instrucciones de los autores, pero sin la intervención directa de los mismos.

Las preguntas planteadas en los cuestionarios pueden agruparse en cuatro bloques. En primer lugar, antigüedad, tamaño, nivel de anclaje territorial, principales productos y mercados, factores de competitividad y principales clientes y proveedores. En segundo lugar, relaciones con otras empresas y asociaciones empresariales y coordinación público-privada. En tercer lugar, la concepción empresarial de la innovación, la capacidad de aprendizaje y de absorción, dificultades de acceso de los actores periféricos a las redes científico-tecnológicas. También se considera en este bloque la naturaleza y evolución de las redes de innovación: vinculación empresarial con universidades y centros científicotecnológios y de formación. En cuarto lugar, los valores imperantes en el clúster y cómo los valores de la ES pueden ser un vehículo del cambio. Estas cuestiones permiten conocer, de un lado, la organización, el grado de especialización y división del trabajo de la cadena de valor, y de otro, los factores de inercia y de cambio en el clúster.

\section{Organización y cambio del clúster: El papel de los valores de la economía social}

A partir del marco teórico esbozado, en este apartado dedicado al análisis empírico del clúster de la caña de azúcar de Veracruz se van a contemplar un conjunto de aspectos y problemas, la mayor parte de los cuales han recibido escasa atención en la literatura sobre clústeres agroindustriales en regiones y países en desarrollo como México. En primer lugar, se mostrará el dominio de los ingenios en la organización del clúster de la caña de azúcar y su fuerte conexión con el poder político. En segundo lugar, y vinculado a esta proximidad de los poderes económicos y políticos, se argumentará el fuerte sesgo pro-producción agraria (variedades, cultivo, plagas, protección ambiental) de la innovación, tanto por parte de los ingenios como de la política de innovación. En tercer lugar, se evidenciará que la concentración productiva de la cadena de valor y la propia concentración del gasto público en I+D+i han generado la fragmentación del conocimiento del clúster. Esto se refleja en el carácter selectivo de las redes de relaciones entre los actores de la cadena de valor y los diferentes tipos de instituciones de investigación y formación sobre la caña de azúcar. En cuarto lugar, se mostrará cómo esta política de innovación que contribuye a la fragmentación del conocimiento y de la cadena de valor, se ve reforzada por las políticas de precios influidas por los acuerdos comerciales de país y por los 
contratos de los grupos de presión internos y externos. Pero todo ello no ha impedido, como se explicará en un quinto punto, la emersión de empresarios imbuidos de los valores de la economía social, que están impulsando la conformación de nuevas redes de innovación, la redefinición de la cadena de valor y una inserción externa del clúster que pone en valor los conocimientos internos.

\subsection{La caña de azúcar en la región centro de Veracruz (México): El dominio de la cadena de valor y la integración vertical del sector por parte de los ingenios}

En la actualidad, México es el sexto productor de caña y el octavo productor de azúcar a nivel mundial. A nivel interno, el cultivo de la caña de azúcar ocupa el segundo lugar en cuanto a generación de valor, después del maíz. La producción se concentra en seis regiones, sumando entre ellas un total de entre 800 a 900 mil hectáreas cultivadas (ISO, 2017). El presente artículo se centra en la región Golfo-Córdoba y Papaloapan, en la parte central del Estado de Veracruz, que ocupa, con el $42 \%$ de la producción de caña de azúcar, el primer lugar a nivel nacional, gracias a que en ella se asientan 20 de los 51 ingenios del país.

Al hilo de lo anterior, en este apartado se intenta mostrar que la organización del clúster de la caña de azúcar de Veracruz (México) gira alrededor del proceso de concentración, tanto inter-sectorial como intra-sectorial, que existe en la cadena de valor protagonizado por los ingenios. Un proceso que ha frenado la especialización y la división del trabajo y ha conducido a una fuerte integración productiva, pero también a una fragmentación polarizada del conocimiento. La polarización tiene lugar entre los ingenios (centrales azucareras), de una parte, y los productores de caña y las Pymes (que son los proveedores de la industria auxiliar de maquinaria y de otros servicios), de otra. La cuestión clave es que los ingenios ejercen una gran influencia sobre los productores de caña (fundamentalmente) pero también sobre una parte de los proveedores industriales. Como consecuencia de esta influencia, el sesgo innovador de los ingenios hacia la producción de azúcar, no favorece el desarrollo de otras formas de innovación, ni la movilización del conocimiento en torno a los nuevos usos de la caña que se encuentra en este segundo grupo de actores.

La CV (cadena de valor) agroindustrial azucarera se extiende a través de las actividades de producción, transformación e intercambio, hasta llegar al consumidor final que se encuentra principalmente en los países que conforman el Tratado de Libre Comercio de América del Norte (en adelante, TLCAN). La complejidad de la CV le permite adquirir un cierto nivel de valor añadido, aunque las fases que agregan más valor tienen lugar fuera de la región. En efecto, en el clúster que nos ocupa, la mayor parte del azúcar se vende como un producto genérico, básico, y sin mayor diferenciación. El cultivo de la caña es muy simple y presenta una gran diversidad dependiendo de la geografía y tamaño de la propiedad, pero también de la cultura y de los medios económicos y tecnológicos del productor. En la región de Veracruz, la caña se recoge entre los meses de noviembre y mayo. En general, la producción de caña es realizada por agricultores, que la venden a los ingenios, o por los propios ingenios. Aunque puntualmente han aparecido algunos agricultores que también transforman su propia caña. 


\section{LOS VALORES DE LA ECONOMÍA SOCIAL COMO IMPULSORES DEL CAMBIO EN CLÚSTERES CON FUERTE FRAGMENTACIÓN DEL CONOCIMIENTO: EL CASO DE LA CAÑA DE AZÚCAR DE VERACRUZ (MÉXICO)}

Los ingenios presentan actualmente diferentes formas societarias o de organización empresarial. De una parte, se encuentran los ingenios que pertenecen o tienen participación accionarial de grupos transnacionales. También están los corporativos o grupos nacionales. $Y$, de otra parte, se encuentran los ingenios que son entidades independientes de carácter familiar. Existen otras diferencias entre los ingenios. Los más poderosos de ellos, que forman parte de los grupos empresariales transnacionales, importan de EUA (Estados Unidos de América) diferentes insumos y sustitutivos del azúcar a partir de los cuales otras firmas del grupo elaboran bebidas, chocolates, galletas, dulces y alimentos diversos. Algunos grupos de ingenios, además, envasan el azúcar para su venta al por menor o menudeo en el mercado del TLCAN; otros ingenios venden su producción a intermediarios. La CV de la caña de azúcar también incluye las actividades de apoyo como son el suministro de insumos, los servicios, el financiamiento y el desarrollo de los recursos humanos y técnicos que se emplean en las actividades del sector.

Dentro del clúster de la caña de azúcar, la producción agraria se desarrolla básicamente en dos tipos de explotaciones: de un lado, la micro propiedad (ejidos) y, de otro, el latifundio, que normalmente es propiedad de los ingenios (Comunicación personal con un investigador de la Universidad Veracruzana, 2017). El cultivo de la caña en los minifundios suele ser una actividad económica secundaria, poco rentable, que ha continuado a través de los años como un hábito por la simplicidad de su producción. De las entrevistas con directivos de los ingenios y testigos privilegiados en 2017 y 2018 , se deduce que, por lo general, este tipo de plantaciones están desatendidas, no se invierte dinero en ellas y son poco productivas. Pero la siembra de la caña es, al mismo tiempo, rentable porque por ley la producción tiene un precio garantizado y, además, se contemplan una serie de prestaciones sociales para los agricultores-productores y para los cortadores de caña, tales como seguridad social y pensión de retiro. Recientemente, se observan cambios en la propiedad de las fincas que apuntan a la concentración de tierras en un solo dueño, los ingenios, lo que define a su vez una tendencia a la integración vertical en todas las fases del proceso productivo. Esto acelera el desplazamiento hacia la marginalidad y el aislamiento de los pequeños productores. Cada ingenio recibe caña de cientos 0 miles de agricultores productores de caña, lo que dificulta el trato individual con los mismos, por lo que es necesaria la intermediación de las asociaciones de productores. La ley obliga a los proveedores de caña a estar afiliados a alguna asociación. Así, los minifundistas o ejidatarios están afiliados a la CNC (Confederación Nacional Campesina), mientras que los medianos productores pertenecen a la CNPR (Confederación Nacional de Propietarios Rurales). Las dos confederaciones están afiliadas al PRI (Partido Revolucionario Institucional). Aunque ambos colectivos están dedicados al cultivo de la caña, existen entre ellos diferencias ideológicas, socio-culturales, tecnológicas y organizativas de consideración. Por otra parte, en esta región los ingenios se encuentran muy cercanos unos a otros, lo que los hace competir entre ellos por la cosecha de los campos próximos a la fábrica y permite a las asociaciones de productores pactar con algunas ventajas, en su condición de proveedores.

En cada ingenio, el comité de producción está formado por el gerente del ingenio y los representantes de las dos asociaciones cañeras, CNC y CNPR. El cometido de los líderes de las asociaciones cañeras es representar a los agricultores ante el comité, el cual se encarga de la gestión del cultivo y 
de la cosecha junto a los ingenios, quienes descuentan a cada agricultor una cantidad por tonelada de caña suministrada: los denominados "gastos prorrateables". El dinero que se obtiene por este concepto, y al que los líderes cañeros tienen acceso directo, no requiere de justificación alguna.

\subsection{La fragmentación/integración del conocimiento: Redes de innovación y línea única de investigación en el sistema científico-tecnológico}

En paralelo a la concentración de la cadena productiva dentro del sector azucarero en torno a los ingenios, se ha producido una concentración del gasto público en l+D+i en favor de los mismos subsectores integrados por dichos ingenios (entrevista con miembro del comité I+D del Centro de Investigación y Desarrollo para la Caña de Azúcar (CIDCA, 2017). Con esta pauta evolutiva se reducen las oportunidades para el resto de los actores de la cadena de valor en cuanto a especialización y división del trabajo. Uno de los sesgos más comunes que se observan en el territorio es que, por lo general, la mayoría de los actores públicos y privados involucrados en las políticas públicas de desarrollo económico o social, muestran un exceso de confianza en el conocimiento externo y en la tecnología importada. De este modo, asumen que la innovación ha de ser un proceso disruptivo y/o asociado única y necesariamente al avance de la ciencia y la tecnología, y a cargo en exclusiva de las instituciones formales especializadas en su desarrollo (Comunicaciones personales con expertos, 2017 y 2018). Pero esta visión implica un abandono y una minusvaloración de los valores, los recursos locales y del conocimiento interno.

Fundamentada en la idea científico-tecnológica de innovación que promueven los actores centrales, y en la cantidad de conexiones de red que estos últimos atesoran con los centros de I+D, el nuevo conocimiento que se genera va dirigido casi exclusivamente a la producción agrícola y está muy focalizado en aumentar la producción de dulce en la caña. Una prueba importante en favor de esta idea lo constituye el hecho de que en México la caña de azúcar sea el único cultivo con una ley (LDSCA 2005) y con un Comité Nacional (CONADESUCA) específicos para coordinar la política pública. Al mismo tiempo, el gobierno federal, por medio de SAGARPA (Secretaría de Agricultura, Ganadería, Desarrollo Rural, Pesca y Alimentación), financia al Instituto Nacional de Investigaciones Forestales Agrícolas y Pecuarias (INIFAP), y al CIDCA, integrando una red de infraestructura pública o parapública de I+D+i que comprende a todas las regiones donde se cultiva la caña. Esta red se ha creado para el sector con la colaboración de los grupos de presión representativos de la Cámara Nacional de la Industria Azucarera y Alcoholera (CNIIA) y las asociaciones de productores de caña Confederación Nacional Campesina (CNC) y Confederación Nacional de la Propietarios Rurales (CNPR). Se ha visto más arriba que en virtud de la inserción del clúster en la CGV (Cadena Global de Valor), el azúcar es entregado como un commodity y las transformaciones que le añaden valor se dan sobre todo fuera de la región. De ahí que las líneas de investigación en el clúster sean básicamente agrícolas. Según esta lógica, los institutos de investigación, los centros tecnológicos, los campos experimentales y las estaciones de cuarentena y de hibridación del INIFAP y del CIDCA, están densamente relacionados con los ingenios, quienes siguen rutinariamente sus estrategias de competitividad (Véase tabla 1). Sin 


\section{LOS VALORES DE LA ECONOMÍA SOCIAL COMO IMPULSORES DEL CAMBIO EN CLÚSTERES CON FUERTE FRAGMENTACIÓN DEL CONOCIMIENTO: EL CASO DE LA CAÑA DE AZÚCAR DE VERACRUZ (MÉXICO)}

embargo, se reconoce la importancia de los asesores técnicos en medición de las distintas variables que afectan a la cosecha y al proceso de transformación para la mejora de la productividad (Comunicación personal con ingenieros, 2018). Por otra parte, a los productores de caña, en su condición de actores marginales en la cadena de producción, desinformados y con menos relaciones entre ellos, se les ha alentado a seguir las mismas líneas de investigación existentes (Véase tabla 1). Como consecuencia de esto último, se perpetúa la innovación incremental en el campo y en la fábrica y se deja fuera del sistema de ciencia y tecnología la búsqueda de nuevos productos y de nuevos mercados; precisamente los otros tipos de innovación que pueden permitir aumentar la especialización y la división del trabajo y podrían contribuir a disminuir tanto la fragmentación del conocimiento como la integración vertical de la cadena de producción.

Sin embargo, en el ámbito de las aplicaciones de los sub-productos, han surgido algunas iniciativas exitosas en el desarrollo de nuevas técnicas, nuevas formas de organización y nuevos procesos. Dichas iniciativas contienen un importante potencial de cambio del clúster. De la información obtenida en las entrevistas a empresas de la región se evidencia que las empresas innovadoras, independientes, que están especializadas en algún producto o servicio para el clúster, hacen su propio desarrollo de investigación, ya sea individualmente o relacionándose con proveedores internacionales y empresas afines en otros países cañeros. Los empresarios declaran también que innovan y, sobre todo, promueven la integración del conocimiento (aprendizaje) apoyándose en las universidades y los centros tecnológicos establecidos en el territorio por la vía de la admisión de sus estudiantes para la realización de prácticas profesionales. De modo que, hasta el presente, las relaciones de estas nuevas empresas con dichas instituciones no son tanto de investigación como de incorporación sistemática de sus egresados.

Estos resultados, apoyados en nuestras propias entrevistas, evidencian que unos segmentos de la cadena de valor se relacionan en exclusiva con un conjunto de centros científico-tecnológicos, mientras que otros segmentos hacen lo propio con otros centros (tabla 1). Como no existe comunicación entre ambas redes puede hablarse de la fragmentación del conocimiento. Lo destacable es que, frente a la red dominante hasta el momento, ha aparecido una red alternativa con numerosas conexiones externas de las nuevas firmas creadas. Además, también cabe destacar que las empresas de servicios a los ingenios y las comercializadoras de derivados del azúcar se escoran relativamente hacia esta segunda red con preferencia a la primera. Lo que evidencia el importante papel de impulsores del cambio de las nuevas empresas innovadoras. 


\section{Tabla 1. Cooperación entre el sector de la caña de azúcar y el sistema científico tecnológico regional}

\begin{tabular}{|c|c|c|c|c|c|c|}
\hline \multicolumn{7}{|c|}{ Centros científico-tecnológicos con los que se relacionan los diferentes subsectc } \\
\hline \multicolumn{7}{|c|}{ Conjunto de subsectores de la cadena de valor } \\
\hline $\begin{array}{l}\text { Actores del } \\
\text { sistema } \\
\text { científico- } \\
\text { tecnológico }\end{array}$ & $\begin{array}{l}\text { Asociaciones } \\
\text { de Agricultores } \\
\text { CNC Y CNPR }\end{array}$ & Agroindustria & $\begin{array}{l}\text { Grupos de } \\
\text { ingenios } \\
\text { Y CNIAA }\end{array}$ & $\begin{array}{c}\text { Empresas } \\
\text { de servicios } \\
\text { a los ingenios }\end{array}$ & $\begin{array}{c}\text { Comercializadoras } \\
\text { de productos } \\
\text { derivados } \\
\text { del azúcar }\end{array}$ & $\begin{array}{c}\text { Empresas } \\
\text { Innovadoras } \\
\text { en proceso } \\
\text { o mercado }\end{array}$ \\
\hline \multicolumn{7}{|c|}{ INSTITUCIONES GUBERNAMENTALES } \\
\hline CONADESUCA & No & No & SI & No & No & No \\
\hline CIDCA & SI & No & SI & No & No & No \\
\hline INIFAP & No & No & SI & No & No & No \\
\hline COLPOS & SI & No & SI & No & No & No \\
\hline \multicolumn{7}{|c|}{ UNIVERSIDADES Y FACULTADES } \\
\hline $\begin{array}{l}\text { U.V, Facultad } \\
\text { C. Agrícolas }\end{array}$ & No & No & SI & SI & No & No \\
\hline $\begin{array}{l}\text { U.V, Facultad } \\
\text { C. Químicas }\end{array}$ & No & No & No & No & SI & SI \\
\hline ITESM $^{*}$ & No & No & No & SI & No & No \\
\hline UTCV $^{*}$ & No & No & No & SI & SI & SI \\
\hline
\end{tabular}

CONADESUCA (Comité Nacional para el desarrollo sustentable de la caña de azúcar).

CIDCA (Centro de Investigación y Desarrollo para la Caña de Azúcar).

INIFAP (Instituto Nacional de Investigaciones Forestales Agrícolas y Pecuarias).

COLPOS: (Colegio de postgraduados) Centro público de investigación de la SAGARPA.

U.V. Universidad Veracruzana.

ITESM: Instituto Tecnológico de estudios Superiores de Monterrey. * Institución privada

UTCV: Universidad Tecnológica del Centro de Veracruz. * Institución privada

FUENTE: Elaboración propia en base a entrevistas a actores (2017-18).

4.3. Políticas públicas cortoplacistas, cautivas de los lobbies internos y externos y "sin espacio" para las cooperativas

El sector azucarero que se ha conformado a raíz de la firma del TLCAN se puede definir como un cártel, puesto que a nivel nacional hay un precio de garantía para la cosecha de la caña. Además, existe control tanto sobre el tipo y cantidad de producción (cuotas) como sobre el precio del azúcar para su exportación (Morales, 2017). Esta característica del sector se debe a los condicionamientos que le impone la industria azucarera estadounidense que es políticamente muy influyente. También ejercen gran presión los delegados del Cornbelt, una región del medio-este estadounidense con agri- 


\section{LOS VALORES DE LA ECONOMÍA SOCIAL COMO IMPULSORES DEL CAMBIO EN CLÚSTERES CON FUERTE FRAGMENTACIÓN DEL CONOCIMIENTO: EL CASO DE LA CAÑA DE AZÚCAR DE VERACRUZ (MÉXICO)}

cultura industrializada, primera productora de maíz a nivel mundial y cuna de poderosas e influyentes organizaciones agrícolas dedicadas a hacer lobby (Richardson, 2012). Los acuerdos del TLCAN incluyen los concernientes al intercambio de los endulzantes del jarabe de maíz estadounidense y del azúcar de caña mexicana, preferentemente sin refinar, en los que cada país cuenta respectivamente con ventaja comparativa. A esta red de relaciones de poder, se incorporan los actores azucareros políticamente más fuertes de México, esto es, los grupos corporativos a los que pertenecen los ingenios y que, como se ha avanzado más arriba, operan en la industria alimentaria y refresquera. Por tanto, en México la aplicación de las políticas públicas que debieran promover la prosperidad para todos, están muy sometidas a las presiones de un complejo cabildeo. Por un lado, con los intereses de los ingenios filiales de las empresas transnacionales y de los grandes grupos corporativos que trabajan muy integrados a intereses internacionales (lo que incluye al Cornbelt y a la industria azucarera estadounidense). Por otro lado, se encuentran los grupos de ingenios menos influyentes y los colectivos organizados (en ocasiones infiltrados por el narcotráfico) de las asociaciones de agricultores de caña (Entrevistas con expertos del sector, 2017 y 2018).

En lo concerniente al sector de la caña, se desarrollan a menudo políticas públicas apoyadas en la LDSCA 2005, que persiguen la obtención de resultados a corto plazo, que son un vehículo del cohecho y que tratan de legitimar la actuación de los allegados a los grupos en el poder y a los partidos políticos. Esto incluye la asignación del presupuesto y las líneas de trabajo para l+D+i. Por su parte, los colectivos organizados utilizan su poder político para convenir cuáles son los asuntos más urgentes e inmediatos que les afectan, sin apenas considerar para el desarrollo del clúster los aspectos sociales (lo que exigiría consultar, integrar, compartir, coordinar, aprender, dentro de políticas que fuesen más transparentes). En este marco, lejos de definir una alternativa de cambio, la creación de cooperativas agrícolas se utiliza como una fórmula empresarial colectiva para malversar dinero público y como instrumento de promoción del voto y el clientelismo (Comunicaciones con diferentes agricultores de caña, café y papaya, 2017).

Como consecuencia de todo lo anterior, las instituciones formales y las políticas públicas se insertan en un sistema económico con una dinámica perversa de exclusión de los actores marginales, donde no se aprovechan plenamente los recursos locales y se bloquea el cambio y la innovación en el clúster.

4.4. Los empresarios innovadores utilizan los valores de la economía social como vínculos entre el conocimiento local y la cadena global de valor

Para entender esta dinámica perversa, es necesario reparar en que las redes de relaciones entre actores no solo reflejan todo un conjunto de estructuras de poder. Además de ello, estas redes son portadoras y reproducen una serie de valores y visiones del mundo que, al propio tiempo, integran a personas en colectivos distintos y con frecuencia con dificultades comunicativas entre sí. De ahí que las redes generen un mecanismo de fragmentación, pero también un mecanismo potencial de integración en la medida que sean capaces de superar algunas fronteras relacionales y comunicativas 
entre actores. En este sentido, nuestras entrevistas han permitido confirmar la vital importancia que adquieren en el clúster un conjunto de códigos y de valores morales, en tanto que vectores clave de la definición de la proximidad entre actores (véase tabla 2).

\section{Tabla 2. Factores determinantes del acercamiento entre actores en $\%$}

\begin{tabular}{|c|c|c|c|c|c|c|}
\hline $\begin{array}{l}\text { Tipo de actores } \\
\text { entrevistados }\end{array}$ & $\begin{array}{l}\text { La ética y } \\
\text { los valores }\end{array}$ & $\begin{array}{l}\text { La geografía } \\
\text { y el lenguaje }\end{array}$ & $\begin{array}{l}\text { El conocimiento } \\
\text { y la educación }\end{array}$ & $\begin{array}{l}\text { La forma de } \\
\text { organizarse }\end{array}$ & $\begin{array}{c}\text { El Status } \\
\text { socio-económico }\end{array}$ & $\mathrm{NS} / \mathrm{NC}$ \\
\hline $\begin{array}{l}\text { A) Conjunto de actores públicos } \\
\text { y privados entrevistados } \\
\text { VA: } 53\end{array}$ & 47,1 & 26,4 & 28,3 & 26,4 & 17,0 & 28,3 \\
\hline $\begin{array}{l}\text { Actores gubernamentales } \\
V A: 4\end{array}$ & 100,0 & 0,0 & 75,0 & 0,0 & 25,0 & 0,0 \\
\hline $\begin{array}{l}\text { B) Conjunto de subsectores } \\
\text { de la cadena de valor VA: } 49\end{array}$ & 42,8 & 28,6 & 24,5 & 26,5 & 18,3 & 30,6 \\
\hline $\begin{array}{l}\text { Suministros para el campo VA: } 2 \\
\text { Agricultores tradicionales }\end{array}$ & 100,0 & 0,0 & 100,0 & 0,0 & 0,0 & 0,0 \\
\hline (ejidatarios) VA 21 & 9,5 & 28,6 & 28,6 & 23,8 & 33,3 & 38,0 \\
\hline Agricultores empresarios VA 8 & 25,0 & 37,5 & 0,0 & 37,5 & 0,0 & 50,0 \\
\hline $\begin{array}{l}\text { Agroindustria (Piloncilleros) VA } 3 \\
\text { Grupos de empresas de la industria }\end{array}$ & 100,0 & 0,0 & 0,0 & 66,7 & 0,0 & 0,0 \\
\hline $\begin{array}{l}\text { azucarera (ingenios) VA: } 8 \\
\text { Empresas de servicios a los } \\
\text { ingenios VA: } 7\end{array}$ & 75,0 & 12,5 & 50,0 & 0,0 & 12,5 & 25,0 \\
\hline $\begin{array}{l}\text { Grupo de Empresas } \\
\text { Innovadoras VA: } 5\end{array}$ & 100,0 & 20,0 & 20,0 & 40,0 & 0,0 & 0,0 \\
\hline
\end{tabular}

FUENTE: Elaboración propia en base a entrevistas a actores (2017-18).

En las entrevistas realizadas en la región, se reconoce que el principal factor de acercamiento entre actores lo define la ética y los valores compartidos entre las personas. Como segundo factor de acercamiento se señalan la educación y el conocimiento. El tercero de los elementos que más unen a los habitantes de la región, lo constituyen indistintamente la geografía y el lenguaje junto con las formas de organización. Pero a estos resultados y valoración global subyace un comportamiento muy heterogéneo entre actores, que refleja en realidad la fragmentación del conocimiento en las redes de relaciones (de l+D+i, por ejemplo) y la discriminación en el sector. En efecto, se observa al propio tiempo que las empresas innovadoras y las empresas de servicios a los ingenios reconocen esencialmente el acercamiento de los actores por la ética y los valores, mientras que, para los ingenios y los actores gubernamentales, el conocimiento y la educación también es un factor determinante de 


\section{LOS VALORES DE LA ECONOMÍA SOCIAL COMO IMPULSORES DEL CAMBIO EN CLÚSTERES CON FUERTE FRAGMENTACIÓN DEL CONOCIMIENTO: EL CASO DE LA CAÑA DE AZÚCAR DE VERACRUZ (MÉXICO)}

proximidad. Sin embargo, este último factor es menos señalado por las empresas innovadoras y las empresas de servicios a los ingenios. Esta diferencia se debe a que los actores gubernamentales y los ingenios únicamente se comunican con quienes ostentan su mismo status y/o su mismo nivel de formación, mientras que el otro colectivo no hace distingos relacionales por esta variable pese a tener un elevado nivel formativo. De ahí su carácter potencialmente integrador.

Asimismo, las pautas relacionales con centros científico-tecnológicos son coherentes con el origen local y regional de estas empresas que están impulsando individual o colectivamente la introducción de nuevos tipos de organización empresarial, la especialización y la diversificación de productos y la apertura de nuevos mercados, lo que introduce una mayor complejidad en la CV. Los nuevos actores, inspirados en los valores y principios de la ES, son empresarios que tratan de encontrar modelos de negocio diferentes (en términos de empleo, mercado, productos, gestión y bienestar) a los que ofrecen las tradicionales alianzas jerárquicas entre ingenios, pertenecientes a los grandes grupos industriales, y las asociaciones de productores, que representan el poder establecido. Con todo, estas nuevas iniciativas son infrecuentes dado el adverso contexto socio-económico y el clima de violencia que impera en el territorio, lo que ha supuesto la salida de la población del mismo, en especial de las personas con mayor iniciativa y formación. Así lo subrayan algunos expertos y empresas innovadoras.

La tabla 3 ofrece información de los diferentes subsectores de la CV de la caña de azúcar de Veracruz en lo relativo al tipo de producto, origen de las empresas, mercados y naturaleza del proceso de innovación. Pues bien, a excepción de los ingenios, las empresas que han conseguido expandir la CV más allá de la producción de azúcar, y que además han alcanzado otros mercados, son precisamente este grupo de empresas innovadoras de origen local. Ahora bien, un rasgo esencial que distingue a este grupo del resto de actores tradicionales de la CV es que únicamente elaboran productos especializados. Una explicación de su éxito y capacidad de adaptación dentro del sector es que los propietarios locales han compaginado las innovaciones de producto y de mercado con las innovaciones organizativas y sociales. Estas firmas aportan una innovación social u organizativo-territorial que está basada en gran medida en revisar, desarrollar y utilizar el conocimiento endógeno para conectarlo a la cadena global de valor, lo que incluye la aplicación de los valores humanos que promueve la ES: honestidad, responsabilidad, cooperación, confianza, solidaridad, sentido de comunidad. Sin embargo, estas firmas innovadoras se alejan formalmente de la cooperativa como fórmula jurídica para huir del desprestigio asociado a su utilización espuria. 


\section{Tabla 3. Comportamiento empresarial según subsectores de la cadena de valor y nuevas firmas innovadoras frente al resto}

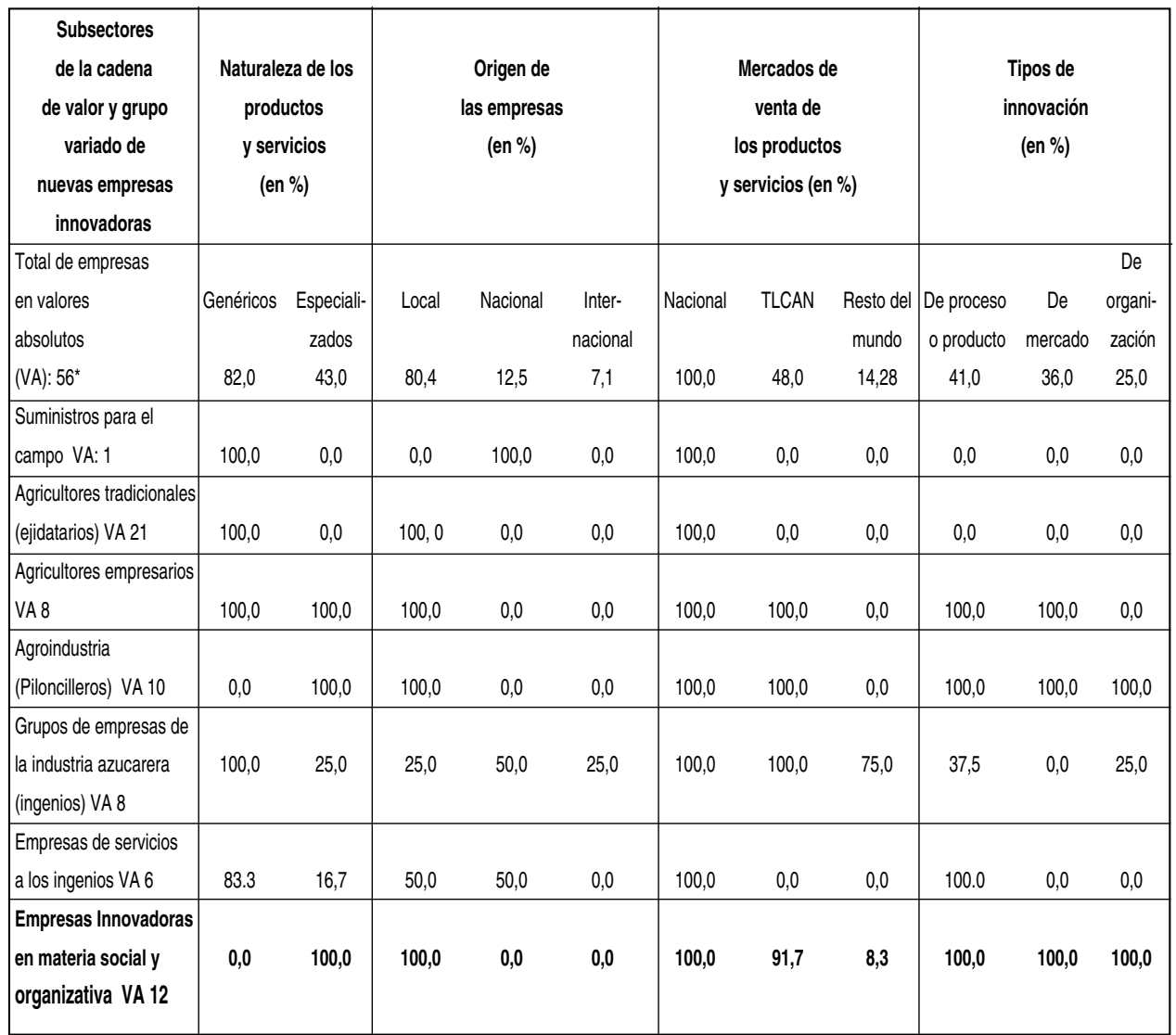

FUENTE: Elaboración propia en base a entrevistas a empresas (2017-18).

A continuación, se van a presentar de forma más precisa algunas de estas iniciativas innovadoras. Antes de ello se indicarán, sin embargo, un conjunto de rasgos compartidos reconocibles por el conjunto de estas firmas a pesar de la diversidad de las mismas. Se trata, en primer lugar, de proyectos empresariales que surgen del ámbito local. Además, son iniciativas más dinámicas en comparación con el resto de actividades tradicionales del clúster. Entre los elementos que respaldan esta última afirmación cabe destacar que suponen una ampliación de la cadena de valor, añadiendo productos y servicios más sofisticados y mejor remunerados. De este modo, proporcionan una mayor renta a los factores productivos implicados en el proceso y un aumento del bienestar de sus socios. 


\section{LOS VALORES DE LA ECONOMÍA SOCIAL COMO IMPULSORES DEL CAMBIO EN CLÚSTERES CON FUERTE FRAGMENTACIÓN DEL CONOCIMIENTO: EL CASO DE LA CAÑA DE AZÚCAR DE VERACRUZ (MÉXICO)}

También suponen introducir mayores dosis de especialización y división del trabajo en el clúster; un elemento capital en la transformación del clúster. A todo ello cabe añadir que estas iniciativas están promovidas por personas jóvenes en su mayoría, con relaciones externas en materia de conocimiento y en posesión de una mayor formación que sus competidores. Hay que subrayar que estas personas jóvenes también están unidas por algunos lazos sociales y el reconocimiento de compartir los mismos valores humanos. Adicionalmente, estas nuevas iniciativas definen organizaciones horizontales y no jerárquicas desde la perspectiva de las relaciones dentro de la firma, dado que los principales trabajadores son los accionistas y funcionan como empresas colectivas 0 asociaciones que introducen en su práctica algunos de los principios de la economía social (Kopel \& Marini, 2016), si bien mayoritariamente de manera informal. Son también entidades de mercado que a veces tienen proyección internacional pero que tienen la particularidad de no pertenecer a grupos transnacionales. En la tabla 4 se sintetizan algunas características compartidas por este grupo de empresas locales innovadoras.

\section{Tabla 4. Características compartidas por las empresas locales innovadoras}

\begin{tabular}{|l|l|}
\hline Naturaleza de las características compartidas & Concreción de las características compartidas \\
\hline Expansión de la cadena de valor & $\begin{array}{l}\text { Productos y servicios especializados. } \\
\text { Mejor pagados (mayor valor añadido) }\end{array}$ \\
\hline Carácter relativamente más dinámico & $\begin{array}{l}\text { Gente joven, mejor formada. } \\
\text { Con vínculos internacionales a universidades, } \\
\text { proveedores, industrias y sectores económicos. }\end{array}$ \\
\hline Lazos sociales & Familia, colegio, antepasados, edad, localidad \\
\hline Mismos valores humanos & $\begin{array}{l}\text { Solidaridad, responsabilidad, cooperación, honestidad, } \\
\text { confianza }\end{array}$ \\
\hline $\begin{array}{l}\text { La práctica natural de algunos principios } \\
\text { de la economía social }\end{array}$ & $\begin{array}{l}\text { Organización horizontal y no jerárquica (democracia) } \\
\text { Ayuda mutua, proceso colectivo de aprendizaje y de } \\
\text { creación de conocimiento. Participación económica } \\
\text { Autonomía e independencia de las autoridades públicas. }\end{array}$ \\
\hline Origen y movilización de los recursos locales & $\begin{array}{l}\text { PYMES } \\
\text { Uso del saber hacer local. }\end{array}$ \\
\hline
\end{tabular}

FUENTE: Elaboración propia en base a entrevistas a empresas (2017-18).

Así, por ejemplo, la Unión de Piloncilleros de Veracruz (UPV), creada en 2015, es una asociación de agricultores que procesan artesanalmente la caña que ellos mismos cosechan para producir piloncillo y lo venden al mercado nacional y estadounidense. El piloncillo es un dulce en forma de cono truncado que se elabora con miel de caña. Asentados en las tierras más altas de la región de Córdoba, los piloncilleros son empresarios de ascendencia italiana (o vecinos de ellos), lo que les confiere cierto rasgo cultural específico que introduce variedad en el sistema territorial. Así, cerca de doscientos productores, hastiados de las asociaciones CNC y CNPR, por su falta de transparencia y los escasos 
beneficios que les proporcionan, se organizaron formalmente siguiendo los principios de la ES para comercializar el producto que fabrican artesanalmente y promover una norma oficial de producción compartida para el piloncillo en cuanto a su proceso y contenido. Así, al tiempo que ponen en valor el saber hacer local, contribuyen a su difusión a través del estímulo a la codificación parcial del mismo vía la fijación de normas técnicas. Además, es importante destacar que las dificultades de accesibilidad física a la zona donde operan los piloncilleros les han conferido independencia, lo que favorece su capacidad para desarrollar una estrategia radicalmente diferente a la dominante.

Fundiciones Balandra, se constituyó en 2010 y está asentada en la región de Córdoba. Sus socios son familiares y profesionales altamente cualificados, que se diferencian del resto de las empresas dentro de su actividad por la calidad de sus productos y el número de certificaciones internacionales que tienen. La empresa ha utilizado el saber hacer local en lo relativo a la industria metalmecánica y reconoce la importancia del trabajo que aporta cada uno de sus socios y trabajadores declarando que "todos son estratégicos", en claro contraste con las relaciones jerárquicas y selectivas que predominan en el sector y en el clúster. Se dedican a la fundición y maquinado de piezas, en novedosas aleaciones de hierro y acero para las industrias del sector azucarero, cementero, minero, de bombas y de válvulas. Lo que evidencia la importancia que a veces adquiere en este tipo de iniciativas novedosas la interacción con otros sectores no agroalimentarios como fuente de entrada de nueva información y de estímulo al desarrollo de la creatividad. La empresa está dotada con equipos de última tecnología en todos los procesos. Se relacionan principalmente con la UTEV (Universidad Técnica del estado de Veracruz) que prepara profesionales con un perfil diferente de las carreras tradicionales. Los socios constituyeron la firma al visualizar una oportunidad de especialización en las industrias del clúster. Tiene clientes en México, Estados Unidos, Canadá, Centro América y El Caribe.

Mastevia, fundada en 2015, es una empresa de origen cordobés, cuyos socios-trabajadores son amigos de la misma edad y profesionales de diferentes áreas (administración e ingenierías química, industrial y de alimentos). Los socios recurrieron a su espíritu emprendedor y a la tradición local en la fabricación de azúcar, se reunieron motivados por la necesidad de tener un trabajo y constituyeron esta empresa que funciona con los principios y valores de la ES. Está dedicada a la elaboración de un edulcorante $100 \%$ natural y de productos alimenticios bajos en calorías. Esta firma contribuye al desarrollo del sector cañero introduciendo una nueva y novedosa forma de consumir azúcar, con menos calorías y más natural e impulsando el cultivo y la comercialización de estevia en el Estado de Veracruz.

Como se avanzaba más arriba, las iniciativas empresariales que acaban de presentarse, se apartan del sistema científico-tecnológico de financiación gubernamental. Y al propio tiempo exhiben otros tipos de innovación diferentes de las científico-tecnológicas y favorecen la integración del conocimiento de otros sectores de la población local, colaborando con las universidades de la región. De igual manera, al trabajar con los principios de la ES, van sentando bases sólidas para ampliar la capacidad de desarrollo endógeno en claro contraste con el modelo de desarrollo desde arriba que se ha promovido por las políticas públicas tradicionalmente controladas por la agenda de los actores económicamente más poderosos. 


\section{LOS VALORES DE LA ECONOMÍA SOCIAL COMO IMPULSORES DEL CAMBIO EN CLÚSTERES CON FUERTE FRAGMENTACIÓN DEL CONOCIMIENTO: EL CASO DE LA CAÑA DE AZÚCAR DE VERACRUZ (MÉXICO)}

\section{Discusión y conclusiones}

Buena parte de la literatura sobre clústeres no ha considerado los fenómenos de poder y la desigualdad en la dinámica de los mismos en América Latina (Bas et al, 2008), siendo una importante excepción el trabajo de Rocha (2015). El presente artículo profundiza en la línea abierta por este último trabajo y coloca a las relaciones de poder y los valores en el centro de la explicación de esta desigualdad en los clústeres. El trabajo integra esta problemática de poder y desigualdad con un enfoque evolucionista que permita dar cuenta del cambio.

La principal novedad del artículo estriba en tomar la fragmentación del conocimiento como expresión de esta desigualdad social y económica endémicas, mostrando que tiene su razón de ser en gran medida en la integración vertical del clúster de la caña de azúcar que impediría su modernización. Por tanto, los resultados obtenidos en el clúster de la caña de Veracruz refuerzan la idea de que el desarrollo de los clústeres en las regiones en desarrollo se puede ver frenado por la integración vertical en la cadena de valor, que limitaría la extensión del clúster (Van Dijk y Sverrisson 2003:199-200). Y ello porque esta integración obstaculizaría la especialización y la división social del trabajo necesaria para diferenciar el producto del clúster y mejorar su posición en las cadenas globales de valor y de mercancías. Ahora bien, nuestro artículo ofrece dos precisiones importantes a esta literatura. En primer lugar, respecto a este último estudio muestra que una problemática de fragmentación/integración del conocimiento permite conceptual y empíricamente evidenciar que estos clústeres pueden tener capacidad para ir desarrollando mecanismos de innovación que vayan creando nuevos espacios de cooperación. En este sentido, y esta es la segunda cualificación esencial, en contra de lo que indica Rocha (2015) al respecto, el problema de los clústeres en América Latina no es necesariamente la ausencia o debilidad de la cooperación horizontal (es decir, entre empresas que realizan la misma fase productiva dentro de la cadena de valor). De nuestro análisis, se deduce que a veces el problema radica más bien en el "exceso" de cooperación. Por ejemplo, las asociaciones de productores de caña y de ingenios son muy fuertes y mantienen un tipo de lazos con el poder político que reproduce el inmovilismo del clúster. El artículo ha ofrecido pruebas de que el problema tiene lugar cuando las redes de cooperación y su fragmentación no reflejan tanto la proximidad en términos de conocimiento de sus miembros sino más bien un mero grupo de interés para conservar el poder. Pero la nueva cooperación que está surgiendo en el clúster sí tiene un carácter más complejo a este respecto y sí responde en buena medida al común denominador de querer poner en valor un nuevo tipo de conocimiento.

Desde esta perspectiva, una hipótesis que se refuerza con el artículo es que en un clúster como el de la caña de azúcar de Veracruz (México) el proceso de innovación tecnológica requiere necesariamente de un proceso previo de innovación social. Un proceso de innovación que, además de suponer un cambio en las relaciones sociales y de dar respuesta a necesidades no cubiertas, debería tener 
un carácter inclusivo, como han destacado Marques et al (2018). En este sentido, el artículo ha evidenciado que en el estado actual de las relaciones de poder económico y político existentes en el clúster de la caña de azúcar, las iniciativas de creación de cooperativas (como una posible expresión de innovación social), lejos de constituir un vehículo de inclusión social y económica, acaban siendo presa de un proceso de captura por los intereses económico-políticos dominantes. No obstante, el artículo ha evidenciado que los valores de democracia, participación y compromiso con la comunidad que destilan el conjunto de entidades que conforman la economía social (Chaves y Monzón, 2018) sí podrían ser un vector apropiado de innovación social, destacando así el papel motor de los valores alternativos a los dominantes como una vía de innovación social apenas destacada por la literatura. Y cabe precisar de qué tipo de innovación social estamos hablando. Así, Marques et al (2008: 503) han conceptuado un tipo de innovación social complementario (al mercado y al Estado) atribuyéndola con frecuencia a entidades del tercer sector y a iniciativas basadas en la comunidad, que según estos autores pretenderían mejorar ciertos bienes y servicios, pero sin cuestionar las estructuras institucionales y las relaciones de poder imperantes. Pues bien, nuestro caso evidencia que la actuación en el ámbito de la innovación social por las nuevas empresas y asociaciones impregnadas de los valores de la economía social caería más bien dentro de la categoría propia de una innovación social radical en el sentido de que se trata de iniciativas que se desarrollan dentro de estructuras socio-económicas más amplias, pero que al mismo tiempo desafían a los poderes públicos y privados que ostentan el poder (Marques et al, 2018:502-503). Bien entendido que se trata de una innovación social radical, en el fondo, por la diferente visión del mundo y los valores que la informan. Aunque por el momento no suponen un desafío efectivo a los poderes económicos y políticos establecidos, por tratarse de un movimiento relativamente modesto.

En este sentido, en los últimos años se ha detectado la emergencia en el clúster de la caña de azúcar de Veracruz de una serie de iniciativas emprendedoras individuales (empresas) y colectivas (asociaciones) que no solo suponen una forma de ligar el emprendimiento con la innovación en el clúster, sin cuestionar las relaciones de poder (Bas et al, 2008). Se trata de procesos de emprendimiento que tratan de constituir una respuesta al poder económico y político dominante y que suponen dar la voz (inclusión y participación) a un tipo de actores y de conocimiento local esencialmente tácito hasta ahora excluidos, al tiempo que inauguran una nueva forma de interacción con el conocimiento externo. $Y$ ello pese a que estamos ante iniciativas lideradas por personas con un elevado nivel de conocimiento formal. Todo lo cual constituye la base de una mayor división del trabajo y especialización de la cadena de valor y del clúster, que conducen al desarrollo de nuevos productos y de nuevas competencias y relaciones. En este sentido, aunque en este tipo de clúster, el formar nuevas redes de innovación se enfrenta al gran problema de tener que redefinir la frontera entre redes sostenidas por actores que constituyen auténticas castas (Van Dijk \& Sverrisson, 2003:191), se evidencia que esto no es necesariamente un obstáculo insalvable. Así, pues, aun bajo estas severas restricciones, la caña de azúcar constituye no solo un ejemplo de modernización y transformación del clúster en gran medida mediante la movilización de recursos latentes que se encontraban hasta ahora dispersos y poco utilizados por en el territorio (Hirschman, 1961). También supone un proceso que podría abrir la puerta a una dinámica de integración de algunas redes de innovación, hasta ahora fragmentadas, lo que tam- 


\section{LOS VALORES DE LA ECONOMÍA SOCIAL COMO IMPULSORES DEL CAMBIO EN CLÚSTERES CON FUERTE FRAGMENTACIÓN DEL CONOCIMIENTO: EL CASO DE LA CAÑA DE AZÚCAR DE VERACRUZ (MÉXICO)}

bién apunta hacia un desarrollo de base endógena. Este resultado coincide con algunos otros procesos recientes de integración parcial de las redes de innovación y de recuperación parcial del conocimiento tácito local, como ocurre en el clúster de los cosméticos de Medellín (Castro-Ramírez et al, 2019). Ahora bien, existe un claro contraste entre este último caso donde el cambio se ha producido por el impulso de la actuación pública y privada planificada de gestión del conocimiento, y nuestro caso que es un proceso claramente espontáneo y desde abajo.

Un tema crucial que este último contraste sugiere para nuevas investigaciones, es en qué medida serán sostenibles en el tiempo los procesos de innovación bottom-up que se están produciendo en la caña de azúcar en ausencia de algún tipo de actuación política top-down que legitime estos procesos y contribuya a su extensión en el clúster, a ser posible creando nuevos espacios de interacción creativa con las redes económicas y políticas dominantes. Ligado con esto último, el artículo también puede contribuir a alimentar una literatura en germen que vincula la riqueza del conocimiento local y la innovación social. Este artículo evidencia que la utilización del conocimiento local no siempre es un proceso suave, sino que puede ser conflictivo. Desde esta perspectiva, las políticas públicas deberían generar espacios de confluencia de intereses entre las redes de actores en conflicto para propiciar una dinámica de integración del conocimiento (Gallego-Bono, 2016). Pues bien, algunos trabajos que han estudiado las políticas top-down de estímulo a la innovación social, muestran la relevancia que adquiere para generar este tipo de innovación el contar tanto con una elevada formación y cualificación de la población local, como con la capacidad de emprender (Jardon y Gierhake, 2017:81). La emergencia espontánea en el clúster de la caña de azúcar de Veracruz de iniciativas privadas con estos atributos ofrece posibilidades para definir políticas, o cuanto menos estrategias inclusivas e integradoras del conocimiento relativamente amplias. No obstante, en futuros trabajos habría que profundizar en la investigación de posibles políticas de estímulo a la inclusión, la confianza y la participación, para estimular a su vez el desarrollo de redes capaces de superar los problemas de fragmentación del conocimiento. Según se deduce del presente artículo, estas políticas de promoción de una gobernanza participativa e inclusiva deben basarse en la transparencia de las instituciones. Esta sería la base de la elaboración de políticas públicas que impulsen los diferentes tipos de innovación y la calidad de vida de los habitantes de la región.

Una de las principales limitaciones de esta investigación radica en que se centra en un único estudio de caso. Sin embargo, el trabajo también se inspira en (y se considera esencialmente extensible a) lo que acontece en otros clústeres agroalimentarios mexicanos (café, papaya, aguacate, berries, etc.). Todos estos clústeres comparten en gran medida un conjunto de arreglos institucionales portadores y reproductores del mismo entramado económico-político considerado en el caso de la caña de azúcar, ligado al TLCAN, pero también un colectivo innovador que podría tener un perfil similar al que aquí se ha evidenciado; aunque establecer este último punto requiere de una investigación especifica. Con todo, no cabe duda, que la comparación con otros clústeres mexicanos y de otros países de la región latinoamericana contribuiría a proporcionar resultados más generales. Esta es una tarea a emprender en el inmediato futuro. 


\section{Referencias bibliográficas}

ACCIONA (2019): Top Países con más desigualdad económica. Recuperado el 8 de Julio de 2019 de: https://www.sostenibilidad.com/desarrollo-sostenible/top-paises-desigualdad-economica.

ALBURQUERQUE, F. (2006): Clústers, territorio y desarrollo empresarial: diferentes modelos de organización productiva, San José, Costa Rica: Banco Interamericano de Desarrollo.

ASHEIM, B.T. \& COENEN, L. (2005): "Knowledge bases and regional innovation systems: Comparing Nordic clústers", Research Policy, 34(8), 1173-1190, DOI: 10.1016/j.respol.2005.03.013.

BALDOVINO, E. \& NAVARRO, J. (2007): Perspectivas de mercados agroindustriales para productos potenciales de Bolívar: los casos del mango y la palma de aceite, Cartagena D, Colombia: Cámara de Comercio de Cartagena, Impresión: Alpha impresores Ltda.

BAS, T.G., AMOROS, E. \& KUNC, M. (2008): "Innovation, Entrepreneurship and Clusters in Latin America Natural Resource - Implication and Future Challenges", Journal of Technology, Management \&Innovation, 3(3), 52-65, DOI: 10.4067/S0718-27242008000200005.

BELUSSI, F. \& SEDITA, S.R. (2012): "Industrial districts as open learning systems: Combining emergent and deliberate knowledge structures", Regional Studies, 46(2), 165-184, DOI: 10.1080/00343404.2010.497133.

CABRA DE LUNA, M.A. (2012): Dictamen del Comité Económico y Social Europeo sobre el tema "La economía social en América Latina", Bruselas, Comité Económico y Social Europeo, NREX/325.

CAPELLO, R. \& FAGGIAN, A. (2005): "Collective learning and relational capital in local innovation processes", Regional Studies, 39 (1), 75-87, DOI: 10.1080/0034340052000320851.

CASTRO-RAMÍREZ, W.D., GADILLE, M., GALLEGO-BONO, J.R. \& RAMÍREZ-CARMONA, M. (2019): "Knowledge management in developing regions: The case of Valle de Aburrá, Colombia". International Journal of Knowledge-Based Development, 10 (2), 128-154, DOI: 10.1504/IJKBD.2019.10022649.

CHAMINADE, C., LUNDVALL, B.Å. \& HANEEF, S. (2018): Advanced introduction to National Innovation Systems, Cheltenham UK: Edward Elgar.

CHAVES, R. \& MONZÓN, J.L. (2018): "La economía social ante los paradigmas económicos emergentes: innovación social, economía colaborativa, economía circular, responsabilidad social empresarial, economía del bien común, empresa social y economía solidaria", CIRIEC-España, Revista de Economía Pública, Social y Cooperativa, 93, 5-50, DOI: 10.7203/CIRIEC-E.93.12901. 


\section{LOS VALORES DE LA ECONOMÍA SOCIAL COMO IMPULSORES DEL CAMBIO EN CLÚSTERES CON FUERTE FRAGMENTACIÓN DEL CONOCIMIENTO: EL CASO DE LA CAÑA DE AZÚCAR DE VERACRUZ (MÉXICO)}

COOKE, P. (2001): "Regional Innovation Systems, Clusters and the Knowledge Economy", Industrial and Corporate Change, 10(4), 945-974, DOl:10.1093/icc/10.4.945.

COOKE, P. (2014): "Systems of innovation and the learning region". En: M.M. Fischer \& P. Nijkamp, P. (Eds), Handbook of regional science, Berlin: Springer-Verlag, 457-474.

COOKE, P. \& MORGAN, K. (1999): The Associational Economy: Firms, regions, and Innovation, Oxford: Oxford University Press.

COOKE, P., URANGA, M.C. \& ETXEBARRIA, G. (1998): "Regional systems of innovation: an evolutionary perspective", Environment and Planning A, 30, 1563-1584.

DAHLMAN, C. (2007): "The challenge of the knowledge economy for Latin America", Journal of Globalization, Competitiveness \& Governability, 1(1). 18-46, DOI: 10.3232 I.GCG.2007.

DOPFER, K. \& POTTS, J. (2008): The general theory of economic evolution, London: Routletge.

EBNER, A. (2010): "Varieties of Capitalism and the Limits of Entrepreneurship Policy: Institutional Reform: Institutional Reform in Germany's Coordinated Market Economy", Journal of Industry, Competition and Trade, 10(3), 319-341, DOI: 10.1007/s10842-010-0086-X.

FERNANDEZ-SATTO, V.R. \& VIGIL-GRECO, J.I. (2007): "Clústers y desarrollo territorial. Revisión teórica y desafios metodologicos para América Latina", Economía, Sociedad y Territorio, 6(24), 859912, DOI: 10.22136/est002007241.

FERRER, A. (2013): "La importancia de las ideas propias sobre el desarrollo y la globalización", Problemas del desarrollo, 44(173), 163-174. DOI: 10.22201/iiec.20078951e.2013.173.36502.

FLORIDA, R. (2014): "The Creative Class and Economic Development", Economic Development Quarterly, 28 (3), 196-205, DOI: 10.1177/0891242414541693.

FREO, M., GUIZZARDI, A. \& TASSINARI, G. (2011): "An insight into the fragmentation of small firms under global competition in a machinery industrial district", International Journal of Globalisation and Small Business, 4(2), 191-205, DOI:10.1504/IJGSB.2011.042253.

GALLEGO-BONO, J.R. (2016): "Fragmentación de las redes de innovación y dinámica de los sistemas territoriales de producción y de innovación en sectores tradicionales", Innovar, 26(62), 23-40, DOI: 10.156 innovar.v26n62.56.

GALLEGO-BONO, J.R. \& CHAVES-ÁVILA, R. (2015): "El modelo cooperativo de sistemas agroalimentarios de innovación: el caso ANECOOP y el sistema citrícola valenciano", ITEA, Información Técnica Económica Agraria, 111(4), 366-383. DOI: 10.12706/itea.2015.023.

GALLEGO-BONO, J.R. \& CHAVES-ÁVILA, R. (2016): "Innovation cooperative systems and structural change. An evolutionary analysis of ANECOOP and Mondragon cases", Journal of Business Research, 69 (11), 4907-4911, DOI: 10.1016/j.jbusres.2016.04.051. 
GALLEGO-BONO, J.R. \& LAMANTHE, A. (2009): "Relations de pouvoir et regulations extra-locales dans l'adaptation des systèmes agroalimentaires au contexte de mondialisation. Une étude de cas France/Espagne", Revue d'Études en Agriculture et Environnement, 90 (2), 185-213.

GALLEGO-BONO, J.R. \& PITXER, J.V. (2012): "La economía política de la concertación social territorial en España y la inclusión/exclusión de la economía social en un contexto de crisis", CIRIECEspaña, Revista de Economía Pública, Social y Cooperativa, 76, 185-213.

GIDDENS, A. (2003): Runaway world: How globalization is reshaping our lives, London: Taylor \& Francis.

GIOVANNINI, M. (2012): "Empresas Sociales en Chiapas: ¿Un instrumento para el buen vivir de los pueblos indígenas?". En: RULESCOOP, Economía Social: Identidad, Desafíos y Estrategias, Valencia: CIRIEC-España, 271-288.

GIULIANI, E. (2007): "The selective nature of knowledge networks in clusters: evidence from the wine industry", Journal of Economic Geography, 7(2), 139-168, DOI: 10.1093 / jeg / Ibl014.

GORENSTEIN, S. y MOLTONI, L. (2011): "Conocimiento, aprendizaje y proximidad en aglomeraciones industriales periféricas. Estudio de caso sobre la industria de maquinaria agrícola en la Argentina", Investigaciones Regionales, 76, 73-92.

GROSSETTI, M. \& BÈS, M. P. (2001): "Encastrements et découplages dans les relations scienceindustrie", Revue française de sociologie, 42 (2), 327-355, DOI: 10.1093/cje/beq001.

HANNAN, M.T. \& FREEMAN, J. (1977): "The Population Ecology of Organizations", American Journal of Sociology, 82(5), 929-964, DOI:10.1086/226424.

HILDRETH, P.M. \& KIMBLE, C. (2004): Knowledge networks: Innovation through communities of practice, Hershey, Igi Global.

HIRSCHMAN, A.O. (1961): La estrategia del desarrollo económico, México: FCE.

ISO, INTERNATIONAL SUGAR ORGANIZATION (2017): ISO. Retrieved 4-28, 2017, from http://www.isosugar.org/sugarsector/sugar.

JARDON, C.M. \& GIERHAKE, K. (2017): "El conocimiento local como factor de innovación social: el caso del distrito municipal de Quito", Investigaciones Regionales, 38, 67-90.

KATZ, J. \& STUMPO, G. (2001): Regímenes competitivos sectoriales, productividad y competitividad internacional, Santiago de Chile: CEPAL-Naciones Unidas, Serie desarrollo productivo, n 103.

KOPEL, M. \& MARINI, M.A. (2016): "Organization and gobernance in social economy enterprises: An introduction", Annals of Public and Cooperative Economics, 87 (3), 309-313, DOI: 10.1111/apce.12138.

LÉVESQUE, B. (1999): Le développement local et l'économie sociale : deux éléments devenus incontournables du nouvel environnement, Montréal: CRISES. 


\section{LOS VALORES DE LA ECONOMÍA SOCIAL COMO IMPULSORES DEL CAMBIO EN CLÚSTERES CON FUERTE FRAGMENTACIÓN DEL CONOCIMIENTO: EL CASO DE LA CAÑA DE AZÚCAR DE VERACRUZ (MÉXICO)}

LÉVESQUE, B. \& LAJEUNESSE-CREVIER, F. (2005): "Innovations et Transformations Sociales dans le développement économique et le développement social", Cahiers du CRISES - Collection études théoriques, 37, Université du Québec à Montréal.

LEWIS, W.A. (2004): Development planning. London, Routledge.

LÓPEZ-CLAROS, A. (2014): "The ends and the means of the development. The samurai and the globalization: does culture matters for development?". Retrieved from augustolopexclaros.blogspot.c a.

LUNDVALL, B.Å. (2010): National systems of innovation: Toward a theory of innovation and interactive learning, London UK: Anthem Press.

LUNDVALL, B.Å., JOSEPH, K.J., CHAMINADE, C. \& VANG, J. (Eds.) (2011): Handbook of innovation systems and developing countries: building domestic capabilities in a global setting, Cheltenham UK: Edward Elgar.

MARKUSEN, A. (1999): "Fuzzy concepts, scanty evidence, policy distance: the case for rigor and policy relevance in critical regional studies", Regional Studies, 37(6-7), 701-717, DOI:10.1080/00343409950075506.

MARQUES, P., MORGAN, K. \& RICHARDSON, R. (2018): "Social innovation in question: The theoretical and practical implications of a contested concept", Environment and Planning C: Politics and Space, 36(3), 496-51, DOI: 10.1177/2399654417717986.

MARTIN, R. \& SUNLEY, P. (2003): "Deconstructing clusters: chaotic concept or policy panacea?", Journal of Economic Geography, 3(1), 5-35, DOI: 10.1111 / j.1944-8287.2009.01056.x.

MOLINA-MORALES, X., MARTÍNEZ-FERNÁNDEZ, M.T. \& COLL-SERRANO, V. (2012): "La eficiencia y la innovación en las subredes de empresas. Un estudio del distrito cerámico de Castellón", Innovar, 22(46), 111-127.

MONTES, V.L. (2012): "El reconocimiento de la Economía Social y de sus valores en la sociedad". En: RULESCOOP, Economía Social: Identidad, Desafíos y Estratégias, Valencia: CIRIEC-España, 363-373.

MOULAERT, F., MACCALLUM, D., MEHMOOD, A. \& HAMDOUCH, A. (Eds.) (2013): The International Handbook on Social Innovation, Cheltenham \& Northampton: Edward Elgar.

NELSON, R. (2016): "Economic Development as an Evolutionary Process". En: E.S. Reinert, J. Ghosh, \& R. Kattel, Handbook of Alternative Theories of Economic Development, Cheltenham \& Northamptom, UK \& USA: Edward Elgar, 323-335.

NELSON, R. \& WINTER, S.G. (1982): An Evolutionary Theory of economic Change, Cambridge, MA: Belknap Press.

NOOTEBOOM, B. (2010): A cognitive theory of the firm. Learning, governance and dynamic capabilities, Cheltenham \& Northamptom: Edward Elgar. 
OCDE (2001): The Well-being Nations. The rol of human and social capital, Paris: OCDE.

PARRA, C. (2013): "Social sustainability: a competing concept to social innovation?". En: F. Moulaert et al (Eds.), The International Handbook on Social Innovation, Cheltenham \& Northampton: Edward Elgar, 142-154.

PERDOMO, I. y IZQUIERDO, H. (2011): "Visión Prospectiva de la Sustentabilidad Agroindustrial". Ninth Latin American and Caribbean Conference (LACCEl'2011), Engineering for a Smart Planet, Innovation, Information Technology and Computational Tools for Sustainable Development, Medellin, Colombia.

PHELS, C., HEIDL, R. \& WADHWA, A. (2012): "Knowledge, Networks, and Knowledge Networks: A Review and Research Agenda", Journal of Management, 38(4), 1115-1166, DOI: 10.1177/0149206311432640.

PORTER, M. (1998): "Clusters and the new economics of competition", Harvard Business Review, 76(6), 77-90.

PORTES, A. (2006): "Institutions and Development: A Conceptual Reanalysis", Population and Development Review, 32 (2), 233-262, DOl:10.1111/j.1728-4457.2006.00117.x.

PREBICH, R. (1981): Capitalismo periférico, México: FCE.

RICHARDSON, N.P. (2012): The politics of abundance: Export agriculture and redistributive conflict in South America, (Doctoral dissertation, UC Berkeley).

ROBINSON, M. (Ed.). (2012): Corruption and development, London \& New York, Routledge.

ROCHA, H. (2015): "Do clusters matter to firm and regional development and growth?: Evidence from Latin America", Management Research: The Journal of the Iberoamerican Academy of Management, 13(1), 83-123, DOI: 10.1108/MRJIAM-12-2013-0534.

ROLDÁN, A., BUSTAMANTE LEMUS, C. \& RAMÍREZ ARGUMOSA, G.S. (2018): "Social exclusion and economic growth in the mexican regions: A spatial approach", Investigaciones Regionales, 40, 57-78.

SCHIUMA, G. \& LERRO, A. (2008): "Knowledge-based capital in building regional innovation capacity", Journal of Knowledge Management, 12 (5), 121-136, DOI: 10.1108 / 13673270810902984.

SCHULLER, T. (2006): "Social Capital, Networks, and Communities of Knowledge". En: B.Kahin \& D.Foray (Eds), Advancing Knowledge and the Knowledge Economy, Cambridge, MA, MIT Press, 75-89.

SEN, A. (2000): El desarrollo como libertad, México: Gaceta Ecológica.

STEINER, M. \& HARTMANN, C. (2006): "Organizational learning in clusters: A case of study on inmaterial and inmaterial dimentions cooperation", Regional Studies, 40(5), 493-506, DOI: 10.1080/00343400600757494. 
TELEVISA NOTICIEROS (2019 01 29): "México reprueba el índice de transparencia internacional". Recuperado el 8 de Julio de 2019 de: https://noticieros.televisa.com/ultimas-noticias/mexicoreprueba-indice-transparencia-internacional-138-corrupcion/

TÖDTLING, F. \& TRIPPL, M. (2018): "Regional innovation policies for new path development-beyond neo liberal and traditional systemics views". European Planning Studies, 26:9, 1779-1795, DOI: 10.1080/09654313.2018.1457140.

TOMÁS CARPI, J.A. (2008): "El desarrollo local sostenible en clave estratégica", CIRIEC-España, Revista de Economía Pública, Social y Cooperativa, 61, 73-101.

TOMÁS CARPI, J.A., GALLEGO-BONO, J.R. y PICHER, J.V. (1999): "Cambio tecnológico y transformación de sistemas industriales localizados: la industria cerámica española", Información Comercial Española, 781, 45-68.

TORRE, A. (2006): "Clusters et systèmes locaux d'innovation. Un retour critique sur les hypothèses naturalistes de la transmission des connaissances à l'aide des catégories de l'économie de la proximité", Régions et développement, 24, 15-44.

TORRE, A. \& WALLET, F. (2013): "Innovation and governance of rural territories". En: E. Coudel, H. Devautour, C.T. Soulard, G. Faure \& B. Hubert (Eds.), Renewing innovation systems in agriculture and food. Wageningen: Wageningen Academic Publishers, 147-164.

TRANOS, E. (2014): "Networks in the innovation process". En: M. Fischer \& P. Nijkamp (Eds.), Handbook of regional science, Berlin: Springer, 489-504.

VAN DIJK, M.P. \& SVERRISSON, A. (2003): "Enterprise clusters in developing countries: mechanisms of transition and stagnation", Entrepreneurship \& Regional Development, 15:3, 183-206, DOI: $10.1080 / 08985620210159239$.

VAN DYCK, B. \& VAN DEN BROECK, P. (2013): "Social innovation: a territorial process". In: F. Moulaert, et al (Eds.), The International Handbook on Social Innovation, Cheltenham \& Northampton: Edward Elgar, 131-140, DOI: 10.4337/9781849809993.00021.

VICK, H.H. (1998): "Desarrollo económico y social” Un enfoque Bahai, Barcelona: Ed Bahai.

WITT, U. (1998): "Imagination and leadership-the neglected dimension of an evolutionary theory of the firm", Journal of Economic Behavior \& Organization, 35(2), 161-177, DOI: 10.1.1.458.9977. 
